\title{
6. PERFIL AMBIVALENTE DE LA FÓRMULA DE REFORMA CONSTITUCIONAL EN LA DIALÉCTICA PERMANENCIA-CAMBIO *
}

\author{
M. ${ }^{a}$ VICTORIA GARCIA-ATANCE
}

Profesora Titular

UNED

* Este artículo corresponde a uno de los capitulos de mi Tesis Doctoral leída en la Facultad de Derecho de la Universidad Complutense de Madrid, el 26 abril, 1989. 


\section{SUMARIO}

I. LA REFORMA CONSTITUCIONAL: ConseCUENCIA DERIVADA DE LA DIALECTICA PERMANENCIA-CAMBIO.-II. LA REFORMA CONSTITUCIONAL. SU FUNCIÓN DE DEFENSA Y GARANTIA DE PERMANENCIA Y SUPREMACIA CONSTITUCIONAL: FACTOR DETERMINANTE EN LA PROTECCION DE LA FORMULA POLITICA O DE IDENTIDAD.-a) Justiticación de la reforma constitucional como instrumento de defensa y garantía no jurisdiccional de la Constitución. b) La reforma constitucional como instrumento explícito de protección de la fórmula política o de identidad de la Constitución. c) La reforma Constitucional como instrumento implicito de protección de la fórmula politica o de identidad de la Constitución. d) Posible incongruencia en la función de defensa no jurisdiccional observada en el ordenamiento constitucional español. III. IDENTIDAD CONSTITUCIONAL: LA FÓRMULA POLITICA COMO ELEMENTO OBJETIVO DE IDENTIDAD CONSTITUCIONAL.a) Concepto de la fórmula política como elemento objetivo de identidad. b) Elementos de la fórmula política. c) Subsistencia de la fórmula política como elemento identificador de la Constitución formal, en la dialéctica permanencia-cambio. d) Consecuencias del reconocimiento de la fórmula política como elemento identificador de la Constitución formal en la dialéctica permanencia-cambio. e) La fórmula política como elemento configurador de límite absoluto al poder de revisión. f) La permanencia del elemento político de la fórmula de identidad como instrumento de subsistencia del orden constitucional. 1) La continuidad del elemento político identificador de la Ley Fundamental, a través de la permanencia del factor ideológico. 2) Alcance de la función interpretativa e integradora de la fórmula de identidad en la Constitución. 3) Disyuntiva del control de constitucionalidad de la actividad de reforma constitucional. 4) Fórmula de identidad como instrumento de control político de la constitucionalidad extrajurisdiccional. 


\title{
6. PERFIL AMBIVALENTE DE LA FÓRMULA DE REFORMA CONSTITUCIONAL EN LA DIALÉCTICA PERMANENCIA- CAMBIO
}

\author{
POR \\ M. Victoria Garcia-Atance
}

Profesora Titular

UNED

La función integradora que asume la Constitución que postulara SMEND ${ }^{1}$, para soslayar la posible divergencia entre la constitución normativa y la constitución real que denunció, Ferdinand LASSALLE $^{2}$ habría de desembocar necesariamente en un resultado que materializa el acoplamiento de dos dimensiones - jurídica y real- de diferente naturaleza pero no contradictorias.

Posibilitar esa armoniosa conjugación es el fin próximo a que aspiran los dispositivos de reforma que prevén las Constituciones rígidas. Sin embargo, no siempre es fácil conseguir un equilibrio, cuando se activan los institutos de revisión, en virtud del cual se permita la adecuación de la Norma Fundamental a las contingencias históricas, pero sin que ello suponga una vulneración de la misma, esto es, sin que tales adaptaciones perjudiquen o distorsionen lo que configura la esencia misma del ordenamiento ${ }^{3}$. En otras palabras, compatibillzar el cambio y permanencia

1 SMEND, R., “El Derecho Constitucional debe garantizar, en su calidad de sistema integrativo el cumplimiento de una tarea que está sujeta a cambio... (...) Este cambio puede tener lugar fuera del propio Derecho Constitucional, siempre que se dé dentro del ámbito social de las fuerzas espontáneas». Constitución y Derecho Constitucional. 1985. Madrid. Centro de Estudios Constitucionales, página 201.

2 Lasalle, F., ¿Qué es una Constitución? Ariel. Barcelona 1984, pág. 84. pág. 533.

3 Lucas Verdú, P., Curso de Derecho Político. Vol. II. Tecnos, Madrid 1977, 
del texto Constitucional, de manera que, aun produciéndose las precisas modificaciones, pueda seguir identificándose en lo sustancial, una determinada norma constitucional, respecto a las demás.

Sin embargo hay que señalar, que aunque la tesis de fondo como es la de conjugar el cambio -al que necesariamente se ven impelidos los textos constitucionales-, y la permanencia -como respuesta a la estabilidad a la que normalmente tienden los Códigos fundamentales-es aceptada ordinariamente por la doctrina, paradójicamente se muestra divergente, en las aplicaciones prácticas de tal supuesto, al negar la existencia de determinados límites, que protegen la constitución material, de la función revisora, al fin de posibilitar su permanencia.

La notable rigidez detectada en el constitucionalismo moderno ${ }^{4}$ conduce a pensar en la cláusula de revisión como medio del que se sirven las Leyes Fundamentales para proyectar su permanencia a lo largo del tiempo, asegurando pues su continuidad, toda vez que se institucionaliza el modelo de rigidez para sus procesos de transformación ${ }^{5}$. Es sabido, como vimos anteriormente, que las Constituciones tienden a reflejar las creencias y los intereses dominantes, o bien los compromisos que liman los intereses en pugna ${ }^{6}$. El Constituyente sitúa este imbricado conjunto de relaciones politico-sociales en el seno del contexto constitucional, con el deseo de garantizarlas o proclamarlas, dotándole de una definitiva condición de rigidez ${ }^{7}$. Afirmar tal evidencia no es nada novedoso, sin embargo, es conveniente hacerlo, aunque sea sólo para centrar la atención en lo que seria el contrapunto a este justificado deseo de permanencia, que, a través de la rigidez, pretende la voluntad constituyente. Efectivamente, a pesar de la tendencia al modelo rígido que parece haber hecho fortuna, si se contemplan los modernos textos constitucionales, se detecta, no obstante por parte de la doctrina, una tendencia que palía los efectos que se derivan del carácter rígido asumido por los Estatuos fundamentales. Nos referimos al pág. 495.

4 Esmein, A., Droit Constitutionnel. Vol. II, $7^{\circ}$ ed. Librairie Recueil Sirey, 1921

5 Bryce, J., Constituciones flexibles y Constitucionales rigidas. Civitas. 2." ed. Instituto de Estudios Políticos, Madrid 1962, págs. 94-95. Las Constituciones flexibles no requeririan dispositivo alguno para su revisión, pudiéndoselas situar, al contrario de como acontece con las rígidas, en los mismísimos principios de las sociedades políticas organizadas frecuentemente; salvo los supuestos en que su flexibilidad derive de la intencionada pretensión del Constituyente, de no dotar de ningún dispositivo en previsión a su reforma, aunque se trate de un texto escrito: como lo configura el supuesto de la Constitución española de 1876. gina 73.

WHEARE, K. C., Las Constituciones modernas. Labor, Barcelona 1971, pá-

7 Bryce, J., Constituciones flexibles y Constituciones rigidas. Civitas. 2. ed. Instituto de Estudios Políticos, Madrid 1962, págs. 94 y ss, op. cit. 
sector que, por propugnar su tesis ignorando el reconocimiento de límites ${ }^{8}$ al poder de revisión, se sitúa como contrapunto, en manifiesta oposición a la tendencia que los propios Códigos fundamentales asumen para asegurar su garantía de permanencia, proyectándose en el tiempo.

Pretender que las Constituciones en su rigidez, lleven al extremo tal condición, de forma que se dificulten en la práctica sus procesos de evolución, por la dificultad que éstos entrañan al punto de que la existencia de una cláusula de reforma, que acoplaria el ordenamiento a las nuevas exigencias político-sociales, se torne ineficaz, es una pretensión poco recomendable. En todo caso, configura uno de los medios más idóneos para que se produzca el resultado que se pretendia evitar: el fin de la Constitución. Pues obviamente, si el instrumento que ha de activarse para producir las modificaciones, lejos de habilitar un mecanismo simple, está dotado de unos dispositivos tales, cuya puesta en práctica hace sumamente difícil su aplicación inmediata, los textos que observen estos sistemas de reforma, como consecuencia de su condición rígida, estarán más fácilmente abocados a que éstos se transformen de todas formas y lo hagan además de manera revolucionaria ${ }^{9}$, sin seguir los procedimientos previstos constitucionalmente a tal efecto.

Pero si poco recomendable es la pretensión de la rigidez excesiva en las Constituciones, al punto que dificultan extremadamente su acomodación a las nuevas necesidades, lo que a nuestro juicio configura un imperativo de primer orden para mantener viva la Constitución, gozando así ésta de verdadera vibración en el contexto social en que se proyecta, menos recomendable, o al menos, igualmente perjudicial para la salud a que todo orden Constitucional debe aspirar, sería el resultado que se derivaría de la inadmisibilidad de límites al poder de revisión, que perfila una corriente doctrinal desde el período de la segunda guerra mundial.

Tal pretensión produciria el efecto fulminante de poner en peligro asimismo el Orden Fundamental, porque igualmente arriesgado sería para el mantenimiento de la Constitución, concretada en el núcleo irreductible que la identifica y define, que la cláusula de revisión no estuviera sujeta a determinados límites que protegieran y defendieran el conjunto de elementos que sustentan la fórmula política ${ }^{10}$ en que se sustancia la Constitución material.

- Esta corriente doctrinal estaría representada por: VANOSI, BISCARETTI DI RUFFIA, entre otros, a quienes hemos mencionado con anterioridad y de cuyas tesis, que propugnan la inexistencia de límites, nos ocuparemos en otro momento del presente trabajo.

- Romano, S., L'ordenamento giuridico. Firenze 1951, pág. 143.

10 Lucas Verdú, P., Curso de Derecho Político. Vol. II, Tecnos, Madrid 1977, 2." ed., pág. 428. 
Se detectaria, pues, una ineficacia de la función revisora como medio para posibilitar la permanencia del texto Fundamental cambiando, cuando, como consecuencia derivada de una condición de rigidez excesiva, provocara el efecto de su cambio, pero además por vía revolucionaria, ignorando los cauces jurídico-formales previstos a tal fin en el texto constitucional, como medios eficaces para recuperar el sentimiento de adhesión constitucional que se ha ido desvirtuando ${ }^{11}$ a consecuencia, probablemente, de las desincronizaciones sobrevenidas entre la Constitución material y la Constitución formal.

De esta forma, se desborda el doble objetivo de permanencia y cambio que pretendía instrumentalizar el dispositivo de revisión: la permanencia se ha extinguido y el cambio se ha llevado a cabo por cauces extrajurídicos. La cláusula de reforma no ha servido para nada en tal supuesto, ya que al activarse ésta sin ser respetados los límites que salvaguardan la supervivencia ${ }^{12}$ de lo que configura la Constitución formal, se produce el efecto de una modificación que lejos de ser competencia del poder de revisión, atañe a lo que configura una atribución exclusiva del poder constituyente, a la que no puede renunciar en el acto constituyente primígeno, lo que se traduciría en lo que BURDEAU denuncia como: "un phénomène qui dépásse largement les limites d'une évolution ou les carateres d'une crise. II y a l'inadaptation d'un concept á une réalité pour laquelle il n'a pas été imaginé».

Esta doble posición que consideramos ha de reflejar la función revisora, nos autoriza a afirmar lo que podria adelantarse ya como una conclusión parcial que se reduciría a lo siguiente: La función de revisión ha de proveer precisamente a la compatibilidad de la permanencia del Estatuto del poder, posibilitando paralelamente su transformación, así como a salvaguardar el núcleo identiflcativo de todo Código Fundamental.

De la eficacia en orden a la consecución de ambos objetivos, podrá, deducirse si la función de revisión responde o no a la dirección asumida por el Constitucionalismo moderno, cristalizado en el establecimiento de un régimen rígido de reforma, que asegure la permanencia del orden constitucional, pero esta permanencia no es realizable si, por otra parte, no se le conecta con los presupuestos identificadores ${ }^{13}$, que sirven de parámetro para dilucidar si las modificaciones que afectan al Texto Fundamental asumen esta condición, en sentido estricto, que implicaría el acoplamiento de

11 Lucas Verdú, P., El sentimiento Constitucional. Reus, S. A. 1985, págs. 131-132.

12 Burdeau, G., "Une survivance: la notion de Constitution», en L'evolution du Droit Public, Etudes en L'honeur d'Achile Mestre. AA.VV. Sirey, 1956, pág. 55.

13 LuCAS Verdú, P., "La fórmula política de la Constitución", en Estudios sobre el proyecto de Constitución. Centro de Estudios Constitucionales, Madrid 1978, pág. 16. 
la Norma Superior a las nuevas exigencias que sobrevengan, o por el contrario, se proyectan como una nueva manifestación constituyente, que obviamente excedería la función revisora, al afectar, precisamente, aquellos presupuestos básicos que identifican el orden constitucional, y cuya modificación llevaría pareja la supresión ${ }^{14}$ de la misma.

Por lo que no podemos renunciar a una valoración bidimensional del significado que asume la función de reforma constitucional, referente, de una parte, a su manifestación como instrumento que habilita los propios procesos de transformación constitucionales, sin que ello obstaculice la permanencia del Estatuto: para segulr siendo debe admitir el ir dejando de ser. $Y$ de otro lado, atendiendo a la función de reforma como dispositivo idóneo para defender y garantizar el elemento identificativo de la Norma Suprema.

\section{LA REFORMA CONSTITUCIONAL: CONSECUENCIA DERIVADA DE LA DIALÉCTICA PERMANENCIA-CAMBIO}

El instituto de revisión constitucional, como vimos anteriormente, está orientado a suplir las deficiencias que toda Norma Fundamental puede experimentar, pero no debe instrumentalizarse sin embargo para un fin que tenga por objeto superar una posible crisis ${ }^{15}$ política, cuya solución a través del dispositivo de revisión implicara la eventual instauración de un nuevo orden constitucional completamente diferente, por producir la desconstltucionalización del sistema político de una comunidad estatal.

El constitucionalismo revolucionario ejemplarizó la tendencia a la permanencia de la Norma Fundamental, en su pretensión de asegurar a las futuras generaciones los hitos conseguidos por el liberalismo constitucional. Este deseo de permanencia se verifica al dotarse, en el Constitucionalismo moderno, a las Constituciones rígidas, de específicos dispositivos para su reforma; el continuo mutar social impone inevitablemente la necesidad del cambio, precisamente para que pueda persistir la Ley

14 Esmein, A., Eléments de Droit Constitutionnel. Tome $2^{\circ}$. Librairie Recueil Sirey, 1921, pág. 501. «Larsq'un peuple a choisi mûrement une forma d'Etat determiné... el est contraire d'inscrire dans sa Constitution la permission de demander a tout moment qu'on change cette forme". En el mismo sentido ScHMITT, C., La teoria de la Constitución, Alianza ed., Madrid 1982, pág. 120; Burdeau, G., Traité de Science Politique. T. IV, Librairie Generale de Droit et Jurisprudence, Paris 1969, pág. 252. 143-144. 
Superior. Ello no hace sino materializar la idea consagrada ya en la Constitución francesa de 1793 en cuyo artículo 28 establece: «Un pueblo tiene siempre el derecho a cambiar, revisar y reformar su Constitución. Una generación no puede someter a sus leyes a las generaciones futuras", generalizándose la conciencia de que bajo ningún concepto puede entenderse la Constitución como ley permanente y eterna ${ }^{16}$. La razón de esta afirmación obedece a tres motivos:

a) por la necesidad de adaptación a la realidad sometida a continua evolución;

b) por el envejecimiento de la norma fundamental a través del paso del tiempo;

c) por las lagunas que se detectan en la Constitución a lo largo de su aplicación práctica.

Frente a procesos constitucionales como el supuesto británico ${ }^{17}$ donde al no existir un Código formal escrito, compatibiliza de manera ejemplar su permanencia adaptándose a la vez a las nuevas necesidades, las Constituciones escritas y rígidas manifiestan la tensión entre permanencia y cambio, de manera patente.

Dicha tensión evidencia ${ }^{18}$ la inevitable tendencia de todo ordenamiento a intentar conciliar ${ }^{19}$ el aspecto estático de sus normas originarias y las orientaciones impresas por las direcciones politicas que los organos constitucionales formulan bajo el impulso dinámico de las fuerzas sociales. Pero más allá de la necesaria adaptación de estos factores - materializándose aquí muy especialmente dicha tensión-, parece primar la tendencia a la permanencia, cuando la adaptación del texto a las nuevas contingencias, tuviera por objeto una transformación que afectara a su régimen político o fórmula política ${ }^{20}$. Lo que es comprensible porque si el constitucionalismo se caracteriza, muy especialmente, por la dinamicidad ${ }^{21}$ de su objeto, no puede por ello minusvalorarse - a pesar de la dinámica de los procesos de integración, continuamente en cambio por la necesidad

16 De Vega, P., La reforma Constitucional y la problemática del poder constituyente. Tecnos, Madrid 1985, pág. 59. pág. 646.

17 Lucas Veroú, P., Curso de Derecho Político. Vol. II, Tecnos, Madrid 1977,

18 Bobbio, N. y Matteuci, Diccionario de Política, pág. 377.

19 Bryce, J., Constituciones flexibles y Constituciones rigidas. 2." ed. Instituto de Estudios Politicos, Madrid 1962, pág. 138.

${ }_{20}$ Lucas Vercú, P., Curso de Derecho Política. Vol. II, op. cit. pág. 428.

21 Heller, H., Teoria del Estado. 6." reimpresión. Fondo de Cultura Economica. México 1942, pág. 267. 
de incorporar en la Constitución jurídicamente normada, los elementos no normados- el carácter relativamente estático que la norma suprema asume, al traducirse en ella la decisión que el constituyente definió.

¿Cómo superar, pues, la tensión existente derivada de la dialéctica permanencia-cambio constitucional?

El concepto de estabilidad ¿asume un sentido quimérico en el ambito constitucional? ¿cabe conciliar ${ }^{22}$ el presupuesto de permanencia, al que tiende toda norma fundamental, con el de su propia transformación?, y en caso afirmativo, ¿hasta qué punto puede predicarse la permanencia de un texto constitucional que transforma sus postulados básicos? Parece que el significado de permanencia implica, tácitamente, la idea de subsistencia del núcleo esencial ${ }^{23}$ de la Constitución, esto es, que las transformaciones que haya de experimentar el texto Constitucional, sean asumidas por éste, en tanto en cuanto permita seguir reconociéndose en aquél las caracterísîcas propias que lo determinan, que son reconocidas por cierto sector de la doctrina como «superconstitución» 24.

En este sentido cabria traducirse la dialéctica permanencia-cambio en verdadera estabilidad ${ }^{25}$, que se proyectaría sobre la base de que el orden constitucional absorbiera tales transformaciones pero activando, a su vez, las fuerzas que hacen posible el mantenimiento del régimen político. Puesto que para que el régimen constituclonal permanezca estable, esto es, que la tensión permanencia-camblo se trueque en estabilidad constltucional, es Imprescindlble ${ }^{26}$ que se produzcan transformaciones Internas, pero suponiendo la continuidad de clertas estructuras.

Esta estabilidad se consigue cuando la Norma Suprema aparece, ante sus destinatarios actuales y los futuros, como relativamente objetivada y despersonalizada ${ }^{27}$, y sólo se logra su permanencia cuando puede mantenerse un equilibrio entre la normalidad y normatividad, durando así la norma más allá del momento presente, esto es, cuando consigue suscitar el sentimiento de adhesión constitucional ${ }^{28}$.

22 Lucas Verdü, P., Cursos de Derecho Político. Vol. II, op. cit., pág. 647.

${ }^{23}$ De Vergottini, G., Derecho Constitucional Comparado. Espasa-Calpe, Madrid 1983, pág. 166.

${ }_{24}$ BaRILe, P., La constituzione come norme giuridica. Profilo sistemático. Firenze 1951, pág. 79 y ss. Barberá editore.

${ }_{25}$ Morlino, L., Cómo cambian los regimenes políticos. Traducción de GoNzALEZ EnCINAR y Centro de Estudios Constitucionales, Madrid 1985, pág. 130.

26 Ibidem, pág. 131.

${ }^{27}$ Heller, H., Teoría del Estado. 6." reimpresión. Fondo de Cultura Económica, México 1942, pág. 273, op. cit.

${ }^{28}$ Lucas Verdú, P., El Sentimiento Constitucional. Reus S.A., Madrid 1985. pág. 66 y ss. op. cit. 
La dialéctica permanencia-cambio, no hace sino evidenciar la tensión existente entre la Constitución material ${ }^{29}$ subyacente y previa a la Constitución formal, y esta última. En la medida en que la Constitución material o sustancial se aleje más de los postulados de la Constitución formal, debido a los imperativos o intereses en juego, o simple evolución ideológica de las fuerzas sociales, que subsisten paralelamente a la vida de la Constitución formal, la brecha entre ambas se acentuará, traduciéndose en un desequilibrio que agudiza la tensión dialéctica permenencia y cambio.

Sí, por el contrario, la diferenciación entre la Constitución material y el Estatuto formal se identifican al punto de acoplarse, la dialéctica permanencia-cambio no suscitará desequilibrio alguno sino que discurrirán al compás de la Constitución integrada, en que Constitución material (equiparable a la idea de cambio) y Constitución formal (representativa de la noción de permanencia) conformarán un equilibrio estático. Las fórmulas de reforma que contemplan las Constituciones rígidas, se perfilan así como instrumentos idóneos para posibilitar el equilibrio entre la Constitución material y la Constitución formal, permitiendo el acoplamiento de ésta a las evoluciones que la realidad social experimienta, pero sin desviarse de las decisiones constituyentes que fueron asumidas en su momento, traduciendo así la Constitución material existente, como conjunto de datos preconstitucionales a la Constitución formal. La fórmula revisora asume así el mérito ${ }^{30}$ de integrar en la realidad constitucional integral que promulgó HELLER, tanto la Constitución formal, como la resultante de las fuerzas extrajurídicas, en una totalidad constitucional equilibrada. En suma, sólo si se encara la función revisora, como auténtica actividad destinada a acoplar la Constitución formal y Constitución material, podrá en puridad hablarse de equilibrio en la dialéctica permanencia-cambio, en la que la reforma constitucional se perfila como una consecuencia de dicha tensión.

Mientras que, si por el contrario, la función revisora, desvirtuando su ejercicio, pretende asumir competencias que sólo al poder Constituyente corresponden - por incidir en determinados aspectos fundamentales que identifican al ordenamiento-, todo posible equilibrio entre el grado de permanencia y cambio deseables se habrá escindido, pues lo que se produce es una supresión de la Norma Fundamental, con lo que toda pretensión de compatibilizar y armonizar la estabilidad y evolución del Instrumento Superior, a través del dispositivo de reforma, se torna ineficaz.

29 Mortatı, C., La Constituzione in senso materiale. Giuffrè ed., Milano 1940, pág. 204.

30 Gomes Canotilho, J. J., Direito Constitucional. 2." ed. Almedina. Coimbra 1980 , pág. 94. 


\section{LA REFORMA CONSTITUCIONAL. SU FUNCION DE DEFENSA Y GARANTIA DE PERMANENCIA Y SUPREMACÍA CONSTITUCIONAL: FACTOR DETERMINANTE EN LA PROTECCION DE LA FÓRMULA POLITICA O DE IDENTIDAD}

La pregunta que se formulara SCHMITT ${ }^{31}$ : "Quién debe ser el guardián de la Constitución» reflejaba, en el período de entreguerras, la insuficiencia de la solución kelseniana de atribuir únicamente a un tribunal de justicia la función de defender la Norma Fundamental. El peligro que vislumbraba Schmitt en tal atribución a la "Aristocracia de la toga» se explica por el temor a que se produjera una politización de la justicia, con el consiguiente desequilibrio en el esquema de distribución del poder.

En el discurso pronunciado por GARCIA PELAYO, con motivo de la solemne sesión de inauguración de nuestro Tribunal Constitucional ${ }^{32}$ manifestaba que: «El Tribunal Constitucional, no es el único órgano encargado de velar y proteger la Norma Fundamental; ni la via jurisdiccional, el único camino para su defensa". Por el contrario, como sostiene TOMÁS y VALIENTE, hay otras instituciones a las que la Constitución encarga la misión de defenderla: el Rey, las Cortes, el Gobierno en determinados supuestos, el Defensor del Pueblo y las Fuerzas Armadas.

Esta misma postura doctrinal es asumida por MORTATI ${ }^{33}$ cuando se refiere a la función de garantía no jurisdiccional que se atribuye a la actividad de revisión. El mencionado autor concreta esta vía ajena al ámbito jurisdiccional en el reconocimiento de unos límites a aquélla, derivados, en parte, del más puro origen iusnaturalista que tuvo eco en el derecho positivo a partir de las cartas revolucionarias francesas, especialmente en el artículo 35 de la Declaración de los derechos del hombre y del ciudadano de 1793: «Quand le gouvernement viole les droits du peuple, l'insurrection est pour le peuple et por chaque portion du peuple, le plus sacré des droits et le plus indispensable des devoirs». Es obvio que la reacción popular a la que se alude, sirve de apoyo para argumentar la exigencia a la conservación de tales principios, que informan un ordenamiento constitucional.

Esta aseveración coadyuva a matizar, al menos en parte, cuál debe ser el núcleo identificador de un determinado orden constitucional, irre-

${ }^{31}$ Schmiтt, C., «Wver dole der Hüter der Verfassung sein?, en Die Justiz 1930-31. Helt 11-12, Bd. VI, 576-628. Cit. en Prólogo de P. de Vega en: La defensa de la Constitución. Tecnos. Madrid 1983, pág. 16.

32 Tomás y VAliente, F., "La defensa de la Constitución", en Revista de Derecho Politico. UNED, n. ${ }^{\circ} 16$. Invierno 1982-1933, pág. 188.

33 Moratı, C., Instituzioni di Diritto Pubblico. Tomo II, nona ediz. Padova, Cedam, 1976, pág. 1254. 
ductible, en consecuencia, por vía de revisión. Esto es, un contenido específico esencial, respecto al que puede y debe ser reconocido un límite al poder de revisión. Su explicación obedece al hecho de que dejar la puerta abierta a cualquier modificación que pueda aplicarse a los derechos fundamentales, - sin entrar de momento en otros aspectos- obra en contra de la función de reforma, mientras que por el contrario, si se sustraen de cualquier posible revisión determinados contenidos constitucionales, sí cabe, entonces, afirmarse que el dispositivo de revisión opera paralelo al de garantía del texto.

Cuando en las Constuticiones alemanas del siglo XIX se preve, junto a otras garantias, un Tribunal de Justicia Constitucional para la protección judicial de la Constitución, se refleja claramente que tal protección judicial de la Norma Suprema no configura sino un sector más, de las instituciones de defensa y garantía instituidas a tal fin, pero revelando, a su vez ${ }^{34}$, el carácter limitado que la institución del Tribunal Constitucional asume, dejando en consecuencia la puerta abierta a otros métodos y tipos de garantizar la Constitución.

La amplitud del concepto con que se entiende la garantía de la Constitución, influye de forma decisiva para que la delimitación de las instituciones implicadas en tal fin, sea de difícil identificación, a lo que sin duda coadyuva, como indica DE OTTO ${ }^{35}$ el hecho de que la noción de garantía constitucional integra dos objetos de protección: el que deriva de la infracción de la Constitución, y por otra parte, el que se refiere a la garantía de permanencia del orden constitucional subyacente, con la consiguiente defensa del mismo, frente al cambio.

En este contexto de reconocimiento de los instrumentos institucionales garantizadores de la supremacía constitucional, de carácter plurivalente y no exclusivo de un único órgano, se sitúa el instituto de revisión constitucional que poseen las Constituciones rígidas, al establecerse en él unas exigencias específicas para su modificación, cuyo procedimiento más - menos agravado, configura un medio idóneo para asegurar una relativa estabilidad del Código Fundamental. De esta forma, la rigidez de la Constitución -reflejada en la cláusula de reforma al objeto de impedir la libre modificación por el legislador ordinario- se revela como un instrumento adicional, de carácter no jurisdiccional, y de extraordinaria importancia en

34 Schmitt, C., La defensa de la Constitución. Tecnos, Madrid 1983, pág. 41. No deja de ser significativo el ejemplo brindado por la Constitución Wurtemburguesa de 1819, cuyo artículo 195 referente a la protección judicial, distingue otras instituciones que coadyuvan a tal fin, soslayándose la exclusividad de la institución judicial.

35 De Otto PaRdo, I., Defensa de la Constitución y partidos políticos. Centro de Estudios Constitucionales, Madrid 1985, pág. 12. 
el objetivo de garantizar el texto constitucional ${ }^{36}$, proyectándose en la defensa de la permanencia de la Constitución material —órmula políticafrente al camblo.

La reforma constitucional adquiere, así, un relieve singular en el fin concreto de proteger la fórmula política en que cristalizó aquella Constitución material en forma jurídica, a través de la Constitución formal. La existencia del instituto de reforma constitucional proyecta así una virtual labor defensora de la Constitución, ya que pretende asegurar a ésta frente al cambio ${ }^{37}$, sobre la base de conferir permanencia e inmutabilidad a los principios que configuran el fundamento nuclear del Orden Constitucional, o elemento identificador del texto.

Y no podría ser de otra manera, porque la propia noción de reforma constitucional viene delimitada por un perfil preciso: no cabe confundir cambio y modificación ${ }^{38}$ de la Norma Superior, pues su efecto sería el de una revolución y una nueva decisión constituyente, con lo que iría en contra de la idea de protección y defensa del ordenamiento, que el instituto de revisión asume; de manera que la función de defensa que proyecta el instituto de revisión se reflejará en la autorización a producir determinadas reformas parciales que no afecten a la fórmula política, pero no en permitir cualquier cambio que incida en el núcleo esencial.

\section{a) Justificación de la Reforma Constituclonal como instrumento de defensa y garantía no jurisdiccional de la Constitución}

Determinadas afirmaciones o definiciones constitucionales son especialmente relevantes, no por el simple hecho de regular competencias concretas, normas técnicas individuales, ni siquiera por constituir una base material para la atribución de las funciones estatales ${ }^{39}$, sino que su verdadero alcance es: que el Estado define a través de éstas, su propio ser y su esencia.

En este sentido, la idea de garantía, en sentido amplio, va referida a la protección de éstas contra todo tipo de eventualidades. A tal fin, todo orden jurídico establece un instituto jurídico al que atribuye, de forma es-

36 Gomes Canotilho, J. J., Direito Constitucional. 2." ed., Almedina, Coimbra 1980, pág. 473, op. cit.

${ }_{37}$ De Otto Pardo, 1., Defensa..., op. cit., pág. 13.

38 CaPITANT, R., Ecrits constitutionnels. Ed. Centre National de la recherche scientifique, Paris 1982, pág. 327.

39 Smend, R., Constitución y Derecho Constitucional. Centro de Estudios Constitucionales, Madrid 1985, pág. 227, op. cit. 
pecífica, esa función garantizadora ${ }^{40}$ destinada a prevenir posibles desvios de la finalidad del ordenamiento.

Sin embargo, la comprobación de que la vía jurisdiccional no agota la función de garantía a la que está sujeta toda Norma fundamental, hace obligada referencia a la justificación del instituto de reforma como otro instrumento, asimismo idóneo, al objeto de proteger el Ordenamiento Constitucional. No en vano algunos ordenamientos, como en el caso italiano, incluyen en el mismo título ambos supuestos: el título VI dedicado "Alle garanzie costituzionale», integra tanto la disciplina de los órganos de justicia constitucional, como la que se refiere al procedimiento de revisión constitucional.

El fundamento que explica su justificación, podemos entenderlo, siguiendo a MORTATI ${ }^{41}$, en base a las siguientes consideraciones:

a) En primer lugar, porque siendo el propio procedimiento de revisión constitucional un elemento constitutivo de la Constitución formal, difícilmente podría considerársele ajeno a la noción de garantía y protección del ordenamiento constitucional.

b) En segundo término, el instituto de revisión constitucional justifica, asimismo, su función coadyuvante de garantía de la Constitución porque sustrae a las leyes de grado inferior toda posibilidad de invadir la competencia de la norma de grado superior, tendiendo así a preservar la identidad e integridad del documento en el cual se consagra la suprema voluntad del Constituyente.

c) Otra razón o argumento que justifica la función garantizadora que asume el instituto de reforma, viene determinada por servir de vía en virtud de la cual, se sustraen de la autoridad del juez constitucional los actos del órgano de revisión, como medio de máxima defensa del núcleo fundamental que caracteriza una determinada Constitución, con lo cual se consigue, indirectamente, soslayar el peligro que engendra su atribución ${ }^{42}$ a la protección judicial.

d) En tercer lugar, por la razón que se deriva de la propia noción de la función de revisión, pues al entenderse ésta como una actividad que tiene por objeto, no sólo posibilitar la adaptación de la norma a las nuevas

40 GALEOTTI, V., «La garanzia costituzionale», en Scritti pel docennale. III, pág. 465, cita MorTATI, Istituzioni di Diritto Pubblico. T. II, nona ed. Padova, Cedam 1976, pág. 1.224.

${ }^{41}$ Mortati, C., Istituzioni di Diritto Pubblico. T. II, nona ed. Padova-Cedam. 1976. pág. 1223 y ss, op. cit.

${ }^{42}$ Schmitt, C., La defensa de la Constitución, op. cit., pág. 41. 
exigencias sobrevenidas en el marco sociopolítico en que aquélla se incardina, sino también preservar la parte estable de la Norma Superior, y no sólo por las especiales dificultades procedimentales de las que se halla investida a tal fin, sino, además, por el sentimiento de responsabilidad que suscita en las clases políticas interesadas en la conservación de la Constitución. Lo cual se hace específicamente patente, precisamente por el carácter de subordinación que, en todo caso, asumen las leyes de revisión - emanadas de un órgano constituido- respecto a la norma fundamental, como resultado que es del poder constituyente.

e) Por último, porque el propio agravamiento del procedimiento es en sí una propia función de garantías ${ }^{43}$-independientemente de la existencia de otros controles jurisdiccionales- que actúa como mecanismo autónomo. El órgano constituyente, al cesar de existir en el momento mismo en que se consolida su obra, debe confiar a otros la custodia de la misma, para que permanezca la voluntad constituyente expresada, proveyendo en consecuencia los medios de revisión que contribuyen a conservar el elemento que identifica la Constitución.

En nuestro ordenamiento la función de defensa que lleva a cabo la reforma constitucional, habrá de conectarse con el precepto definido por artículo 9.1 porque parece reflejarse claramente en él la expresión "Constitución" diferenciada de la de el «resto del ordenamiento jurídico», de forma que, como señala DE OTTO ${ }^{44}$ puede referirse con el primer término a la idea de Constitución material. De manera que difícilmente podría sostenerse que lo que se preceptúa en el mencionado artículo 9.1 -que coadyuva a la defensa del Código Fundamental - entrará en contradicción con el artículo 168; al no establecerse limites absolutos a la función de revisión: «La defensa de la Constitución, por tanto, sólo puede estimarse equilibrada y lógicamente coherente - dice el autor - si la Constitución sustrae a la disponibilidad del legislador aquellos preceptos que positivizan el núcleo del orden constitucional de cuya defensa se trata».

\section{b) La reforma Constitucional como instrumento explícito de protección de la fórmula política o de la identidad de la Constitución}

Reconocida la función de defensa de la Norma Constitucional que asume el instituto de reforma que contemplan las Constituciones rígidas,

43 Mortati, C., Scritti sulle fonti del diritto e sull'interpretatione. Vol. II, Milano. Giuffrè edit. 1972, pág. 17. En el mismo sentido: Spagna Musso, E., Diritto Costituzionale. Principio generali. Padova-Cedam, 1979, pág. 103.

44 De Otto Pardo, I., Defensa de la Constitución y partidos políticos, op. cit., pág. 26. 
proyectándose dicha protección muy específicamente en lo que configura la «Constitución de la Constitución», en feliz expresión del profesor GARRORENA, habrá de referirse a los modos en que esta función protectora se manifiesta.

En este sentido, la defensa de la Constitución a través de la reforma constitucional como instrumento explícito, consistirá en una prohibición de cambio de las normas constitucionales de derecho positivo ${ }^{45}$ cuando éste formula, de manera expresa, las normas - la fórmula política- cuyo cambio prohibe, intentando garantizar así su permanencia, y cuya alteración supondría un atentado a la médula misma del orden constitucional ${ }^{46}$.

Un ejemplo representativo de este supuesto lo configura la Ley Fundamental de Bonn en cuyo artículo 79.3 , se contempla con claridad la función de defensa de lo que configura el núcleo fundamental que identifica dicho ordenamiento constitucional: «Es inadmisible toda modificación de la presente Ley Fundamental que afecte a la división de la Federación de Estado o al principio de la cooperación de los Estados en la legislación o a los principios consignados en los artículos $1 .^{\circ}$ y 20 ." La caracterización de la función de defensa aquí perfilada mediante el dispositivo de revisión, excede de la simple dificultad de un reforzamiento de la rigidez para el supuesto de modificación constitucional, asumiendo tal prohibición, por el contrario, un carácter absoluto, que identifica expresamente el núcleo intraspasable e inmodificable de la Constitución.

Lo mismo cabe afirmarse del artículo 89 , in fine de la Constitución Francesa de 1958 que prohibe expresamente la revisión de la forma republicana de Gobierno; o en el supuesto italiano de 1947 cuyo artículo 139 sustrae expresamente la forma republicana de objeto de revisión.

La inclusión de determinadas cláusulas de intangibilidad en el instituto de revisión, responde, pues, a la idea de defensa que la función de reforma ejercita en torno a la Norma fundamental. Aquéllas actúan como instrumentos protectores ${ }^{47}$ de la fórmula política del ordenamiento, garantizando, frente a hipotéticas reformas, un núcleo o reducto mínimo inquebrantable de las premisas que configuran el "carácter legitimador, fundamentador e interpretador de todo el ordenamiento jurídico».

45 De Otto Pardo, I., Defensa de la Constitución y partidos políticos, op. cit., pág. 13.

46 De Vegottini, G., Derecho Constitucional Comparado. Espasa-Calpe, Madrid 1983, pág. 188, op. cit.

47 LUCAS VERDÚ, "La fórmula política», en Estudios sobre el proyecto de Constitución. Centro de Estudios Constitucionales, Madrid 1978, pág. 25, op. cit. 


\section{c) La reforma constitucional como instrumento implícito de la protección de la fórmula política o de identidad de la Constitución}

Pero la cláusula de reforma proyecta, asimismo, una función de defensa de la Constitución al margen de su formulación expresa. Esto es, la actividad de defensa, a través del instituto de reforma, cabe construirse también dogmáticamente ${ }^{48}$, es decir, sin que medie formulación expresa de límites al poder de revisión, para asegurar, de manera concisa, la garantía de permanencia del núcleo sustancial de la Constitución. Esto se explica porque, como sostiene DE OTTO ${ }^{49}$, el objeto de la defensa de la Constitución no está configurado únicamente por las normas de carácter positivo del derecho Constitucional, sino que se proyecta en orden a la permanencia y protección de la Constitución material subyacente, como fuente inspiradora del acto de decisión constituyente ${ }^{50}$. Según esta formulación, la función de defensa entendida de forma implícita, a través del instituto de reforma, se proyectaría, no ya como sucedia en el supuesto que vimos anteriormente, a través de las normas jurídicas del derecho positivo constitucional, sino por medio de la fórmula política configuradora de un determinado régimen, al que dan forma concreta aquellas normas positivas.

A tal fin, no cabría más alternativa que la de reconocer la existencia de unos límites implícitos que - al margen del silencio constitucionalhabrán de considerarse como existentes y latentes en el telos constitucional, al objeto de garantizar y proteger el elemento identificativo de la norma suprema.

Así, por ejemplo, la proclamación del carácter absoluto de los derechos de la persona que prescribe el artículo 2 de la Constitución Italiana, justificaría la afirmación ${ }^{51}$ de que, impuestos por el constituyente, pueden ser sustraídos al poder de revisión al objeto de garantizar la suprema manifestación de la voluntad del Estado.

pág. 13

De Otto Pardo, I., Defensa de la Constitución y partidos politicos, op. cit.,

49 Ibidem, pág. 13.

so Mortati, C., Studi sul potere costituente e sulla riforma costituzionale deIlo Stato, Raccolta di Scritti. Vol. I, Milano, Giufrrè edit., 1972, pág. 319.

51 lbidem, pág. 319. 


\section{d) Posible incongruencia en la función de defensa no jurisdiccional observada por el ordenamiento Constituclonal español}

Se ha dicho que de las normas programáticas de la Constitución se deriva un vínculo para el legislador, que por la naturaleza de la fuente de la que aquéllas proceden, implican una obligatoriedad para los órganos legislativos en el ejercicio de su actividad ${ }^{52}$, a tenor de las directrices establecidas en tales normas. De esta forma, el Estado mismo se sujeta a perseguir ciertos fines, quedando obligado frente a la Constitución y a la colectividad, a asumir la protección de tales objetivos.

Tal es el supuesto de artículo 3, párrafo segundo de la Constitución Italiana: «Es misión de la República remover los obstáculos de orden económico y social, que, limitando de hecho la libertad y la igualdad de los ciudadanos, impiden el pleno desenvolvimiento de la personalidad humana y la efectiva participación de los trabajadores en la organización política y social del país». Y en el mismo sentido hay que mencionar el artículo 4 de la Constitución Italiana de 1947: "La República reconoce a todos los ciudadanos el derecho al trabajo y promueve las condiciones que hacen efectivo este derecho".

El reconocimiento, pues, por parte del Estado de determinados fines a cuya consecución van dirigidas tales normas programáticas, habrá que relacionarlo con la Constitución en sentido material ${ }^{53}$ que caracteriza un determinado tipo de régimen, y a la que se reconoce eficacia jurídica vinculante y decisiva en la entera acción estatal ${ }^{54}$.

Al expresar estas normas o principios los fines caracterizadores de la constitución material, o fórmula política, dada su inserción en el texto fundamental ${ }^{55}$, obligan a los poderes públicos a su obediencia.

Esta circunstancia cabe, asimismo, predicarse de nuestro propio ordenamiento, en cuyo artículo 9.1 se establece la sujeción a la Constitución -y por tanto a los fines a que tienden los principios constitucionales- asi como la remoción de los obstáculos que los dificulten, artículo 9.2.

52 CRISAFULLI, V., "Le norme programatiche della constituzione", en Studi di Diritto constituzionale in memoria de Luigi Rossi. Giuffrè ed. Milano 1952, op. cit., pág. 71 y ss.

${ }_{53}$ Ibidem, pág. 79.

54 De Vergottini, G., Derecho Constitucional Comparado. Espasa-Calpe, Madrid 1983, pág. 143, op. cit.

${ }_{55}$ Lucas Verdü, P., Curso de Derecho Politico. Vol II, Tecnos, Madrid 1977, pág. 79, op. cit. 
De esta manera, el propio ordenamiento jurídico parece proyectarse positiva y negativamente a la consecución de los fines propuestos a través de determinadas normas programáticas, lo que se traduce, de alguna for$\mathrm{ma}$, como un compromiso de protegerlas y garantizarlas ${ }^{56}$.

Es precisamente en este punto concreto donde surge la posible divergencia de la función de defensa no jurisdiccional a la que se encuentra sometido nuestro ordenamiento constitucional.

Pues, si de una parte, se tiende a la consecución de aquellos fines formulados a través de los principios y, a cuyo objeto el artículo 9.1 y 2 establece sus medios, positiva y negativamente, como vimos, no deja de constituir una contradicción el hecho, en virtud del cual, algunos de los mecanismos jurídicos de defensa de la Constitución, estén al servicio de la protección de los valores políticos ${ }^{57}$-que al informar el ordenamiento, conducen, al combinarse ${ }^{58}$, al establecimiento de los principios que integran la fórmula política-, así como de los principios que legitimen el sistema constitucional, y que paradojjicamente no queden éstos Igualmente amparados por la claúsula de reforma —que configura uno de los medios claves, como vimos con anterioridad, no jurisdiccionales, en la función de defensa de la Constitución- a través de un límite absoluto, que afecte a la fórmula política, en la cual cristalizan aquellos valores y principios del ordenamiento, dejando en consecuencia sin la debida garantía el núcleo del ordenamiento cuya defensa se pretendía con el artículo 9.1 y 2 de la Constitución Española ${ }^{59}$.

Cualquier invocación a la garantía que pudiera derivarse de la cláusula de cuasi-intangibilidad ${ }^{60}$ que se contempla a través del procedimiento superagravado de revisión que prescribe el artículo $168 \mathrm{CE}$, parece, a nuestro juicio, insuficiente, pues como DE OTTO ${ }^{61}$ aduce, la garantía de dicha claúsula cuasi-intangible, podría vulnerarse, si el procedimiento complejo del artículo 168 -que en principio pretende consolidar la defensa de la fórmula política que identifica la Constitución material, se reforma, a su vez, por la vía del 167 CE.

56 Crisafulli, V., «Le norme programatiche della costituzione», op. cit., pág.

79.

57 De VEGA, P., «Supuestos políticos y criterios jurídicos en la defensa de la Constitución: algunas peculiaridades del ordenamiento constitucional español», en Revista de Política Comparada. Universidad Menéndez Pelayo. Primavera-Verano 1984, n. ${ }^{\circ} 10-11$, pág. 413.

58 De Esteban, J., El régimen Constitucional Español. Vol. I. Labor, Barcelona 1980, pág. 53.

59 De Otto Pardo, I., Defensa de la Constitución..., op. cit., pág. 27.

¿ De VegA, P., «Supuestos políticos y criterios jurídicos...», op. cit., pág. 407.

61 De Otto Pardo, I., Defensa de la Constitución..., op. cit., pág. 29. 
Lo que, en suma, conduciría al poco recomendable resultado de que la defensa no jurisdiccional que debiera observar el instituto de reforma, quedara vacía de contenido, al no contar con una verdadera garantía de los postulados en que resposa la fórmula política como elemento identificador del ordenamiento; pero además, una clara contradicción con el compromiso contraído, según el artículo 9.1 y 2, por parte de los ciudadanos y poderes públicos para que los valores y principios de la Constitución puedan alcanzarse, lo cual, como vimos líneas antes, se traduce en un compromiso de protección y garantía de los mismos, tanto por parte de los ciudadanos como por parte de los poderes públicos.

La función de defensa asumida por la reforma constitucional se revela, pues, como el instrumento idóneo que en la dialéctica permanenciacambio, posibilitará la superación ${ }^{62}$ de las crisis evidenciadas en el ordenamiento, pero sin, llegar a modificarlo en sus presupuestos esenciales, manifestándose así como la contestación más conveniente a la demanda de la organización fundamental del Estado, ya que se conjuga la introducción de los mecanismos útiles que devuelven la estabilidad al orden constitucional, pero impidiendo a su vez su desconstitucionalización ${ }^{63}$. En suma, la función de defensa, proyectada hacia la permanencia de la Constitución material se perfila como la síntesis del equilibrio en la ingeniería constitucional, pues de otra forma se produciría el resultado de un ordenamiento entendido como conjunto de normas, de entes, de institutos que traducirían un significado parcial y no unitario ${ }^{64}$ frente a la aspiración de unidad a la que tiende la Constitución material.

La materialización práctica de la previsión de defensa de la Constitución, a través del instituto de reforma, vendrá determinada, por el reconocimiento de la existencia de unos límites al poder de revisión, a los que se refieren, en general, los sostenedores de la supremacía de la Constitución material, para garantizar la continuidad del núcleo esencial cuya alteración supondría un nuevo ejercicio del poder constituyente y no del de revisión ${ }^{65}$.

Desde esta óptica, la concepción garantística se inspira -como aduce ROLLA ${ }^{66}$ - en la tendencia a la que propende la Constitución material,

62 Rolla, G., Riforma delle istituzione e Costituzione materiale. Giuffrè edit. Milano 1080, pág. 138.

63 Ibidem, pág. 139.

B4 BARTOLE, S., "Costituzione materiale e ragionamiento giuridico «en Diritto e Societa, pág. 622. Saggio g. posteriormente sería recogido en los Scritti in onore di Verzio Crisafulli.

${ }_{65}$ Novissimo Digesto Italiano XV. Barile-De Siervo. Voz: Revisione della Costituzione, pág. 776.

${ }_{6 \theta}$ Rolla, G., op. cit., pág. 102. 
al fin de posibilitar la continuidad de los valores que han dado origen a la actividad constituyente.

\section{IDENTIDAD CONSTITUCIONAL: LA FÓRMULA POLITICA COMO ELEMENTO OBJETIVO DE IDENTIDAD CONSTITUCIONAL}

Partiendo de la noción de que la Constitución material no se identifica necesariamente con la Constitución formal por las razones que, como vimos anteriormente, provocan la tensión en la dialéctica permanenciacambio a que se encuentra sometida la realidad constitucional; resulta imprescindible arbitrar un medio de adecuar estas posibles divergencias, pero de manera que no produzca, a su vez, el resultado de desdibujar los presupuestos básicos que, preexistiendo a la Constitución formal, influyeron decisivamente en la formulación de ésta ${ }^{67}$. Esta adecuación garantizará la supervivencia de una Constitución material viva ${ }^{68}$, que habrá de manifestarse como una salida al positivismo escrito, integrando a su vez, los datos sociales existentes en el momento del acto constituyente ${ }^{69}$-anteriores a la norma fundamental - y que subsisten a lo largo de la vida constitucional de ésta.

¿Cómo actuar la norma suprema para que no se impida su evolución, pero sin que aquélla pierda su identidad?

El nacimiento de la Norma Fundamental se traduce en la plasmación en ella de las opciones fundamentales sobre la organización del Estado -Comunidad y Estado- aparato ${ }^{70}$, quedando sujetas a aquel núcleo originario, resultante del juego de las fuerzas políticas que se mueven en la

67 Mortatı, C., La Costituzione in senso materiale. Milano. Giuffré, ed. 1940 , pág. 208, op. cit.

68 Gomes Canotilho, J. J., Direito Constitucional. 2." ed. Almedina. Coimbra 1980, pág. 89, op. cit.

${ }^{69}$ MoRtatı, C., Studi sul potere constituente e sulla riforma constituzionale dello stato. Vol. I. Milano, Giuffré ed. 1972, pág. 319, MoRTATı afirma que el constituyente asume una solemne proclamación de principios que afirman la individualidad del nuevo orden, distinguiéndole así de otra que caracterizaría a otro ordenamiento asumiendo la función de fuente, que requiere, en consecuencia, proceder a la formulación del nuevo orden, con referencia a las premisas fundamentales adoptadas por el constituyente. 136, op. cit.

70 De Vergottini, G., Derecho Comparado. Espasa-Calpe, Madrid 1983, pág. 
Comunidad ${ }^{71}$. Esto es, en otras palabras, la síntesis o selección básica de todos los demás principios de la convivencia social y jurídica.

Efectivamente, si en algún momento es posible que exista la, a nuestro juicio, utópica circunstancia de que el equilibrio de la dialéctica permanencia-cambio, se torne real, será, con seguridad, el momento más próximo al acto constituyente. Pues, al quedar éste condicionado por la realidad subyacente de las fuerzas sociales preconstitucionales, lo más seguro es que, al menos al principio, exista una cierta armonía entre la Constitución material y la Constitución formal.

Sin embargo, el mero desarrollo constitucional a lo largo del tiempo, al estar sometido a los acontecimientos contingentes que hacen evolucionar las fuerzas sociales, produce el efecto de que, lo que al comienzo se manifestaba como equilibrio estable entre la realidad social configurada de la Constitución material y la Constitución formal, se torne insufiente, evidenciándose de nuevo la tensión permanencia-cambio.

Esto no hace sino poner de manifiesto una realidad inevitable a lo largo de la historia del constitucionalismo.

Pues bien, considerando como inevitable el desequilibrio o desarmonía entre la Constitución material y la Constitución formal, que habrá de producirse tarde o temprano, de lo que se trata es de limar o minimizar al máximo la tensión entre la Constitución materlal y la Constitución formal. Lo cual será posible si se modifica la Constitución, pero, y siempre que tal reforma se produzca en base a unos parámetros concretos que encaucen de nuevo de forma armónica y coherente la Constitución material y la Constitución formal. Esos postulados habrán de ser aquellos en los que se manifestó la obra constituyente.

El cauce, pues, que posibilitará la actuación de la Norma Suprema para compatibilizar la dicotomía evolución-permanencia no puede, a nuestro juicio, ser otro que el reconocimiento del núcleo sustancial, «Presuposto esenciale e irreductibile" ${ }^{72}$, fórmula política ${ }^{73}$, como referencia clave que marca y define los parámetros que delimiten la permanencia y/o cambio constitucional, siendo secundario que esté implícita o explícita en el texto constitucional ${ }^{74}$. En esta misma línea se sitúa MORTATI ${ }^{75}$, cuando reco-

71 Zangara, V., «Constituzione materiale e Costituzione convenzionale», en Scritti en onore de C. Mortati. Vol. I, pág. 33.

72 Crisafulli, V., “Por una teoría giuridica dell'indirizzo político», en Studi Urbaniti, 1939, XVII, pág. 64, nota 45.

73 Lucas Verdú, P., Curso de Derecho Politico. Vol. Il, Tecnos, Madrid 1977, pág. 428, op. cit.

${ }^{74}$ Bidart Campos, G., Doctrina del Estado Democrático. Ediciones jurídicas de Europa y América. Buenos Aires 1961, pág. 127.

75 Mortatı, C., Appunti di corso di Istituzioni di Diritto Pubblico 1948-1949. Padova-Cedam 1949, pág. 375. 
noce la imposibilidad de la estabilidad absoluta de la estructura constitucional, debido a las adaptaciones que han de operarse en ésta, pero sin embargo, paralelamente afirma que éstas transformaciones no podrán producirse de manera que produzcan una afrenta o ataque a lo que configura el núcleo auténticamente basilar de la Constifución que define la esencia de un determinado orden y cuyo cambio supondría la caída de todo el orden al que la sirve de apoyo y fundamento. De esta afirmación se desprende la consecuencia siguiente: que la función revisora deberá ceñirse a los postulados fundamentales que la actividad constituyente determinó, de forma que el núcleo sustancial o básico de cada ordenamiento, habrá de coincidir precisamente con el límite o límites que puedan oponerse a la función revisora. En otras palabras, los límites materiales, ya sean expresos o implicitos, a la actividad revisora, corresponden precisamente al elemento Identificado de un orden fundamentall.

घ) Concepto de la fómula política como elemento objetivo de identidad

La noción y estudio de la fórmula política, objeto de brillante tratamiento por el profesor LUCAS VERDÚ, configura el compendio de los datos preconstitucionales que inspiró la obra constituyente, por lo que podría ser identificada con la Constitución en sentido material ${ }^{76}$, entendida como "aquel nucleo essenciale di fini e di forze che regge ogni singolo ordinamiento positivo». Así lo reconoce CRISAFULLI ${ }^{77}$ cuando se refiere a la asunción, por el Estado, de ciertos fines que relaciona con la Constitución en sentido material, que caracteriza un determinado régimen político y a la que se reconoce eficacia jurídica vinculante.

Esta noción de régimen, definido a través de los fines de la Constitución material, es asimismo afirmada por CHIARELLI ${ }^{78}$ cuando la explica como, "L'insieme degli istituti giuridici coordinati allo scopo dell'attuazione di una determinata conzecione politica dello Estato e della Societa».

La representación de lo que configuran los factores extrajurídicos que, en un momento histórico, se unifican en un modo unitario, a través de las fuerzas sociales que interpretan los intereses de la comunidad política,

78 Mortatı, C., La costituzione in senso materiale, op. cit., pág. 87.

7 Crisafulli, V., "Le norme programatiche della Costituzione", en Studi di Diritto Costituzionale, in memoria de Luigi Rossi. Giuffrè, Milano 1952, pág. 71 y ss, op. cit.

78 CHIARELLI, G., Concetto di «Regime» nel diritto pubblico. Archivo Giuridico, 1932, pág. 212. 
vendría definida por la Constitución material. Esto la convierte en la fuente social primígena de la Constitución formal.

Este es el sentido que CROSA ${ }^{79}$ le atribuye, cuando se refiere al fin político de la Constitución, al afirmar que la Constitución se presenta como: "Un complesso di principio diversi, fra loro coordinati e collegati, che servono per il conseguimento di un fine politico preminente nel momento storico in cui la Costituzione si attua».

La traducción jurídica de la Constitución material, en la Norma Fundamental formal, cristaliza en la fórmula política en que se refleja aquella realidad existente, previa a la decisión constituyente.

La fórmula política se traduce como el dispositivo jurídico esencial, que trasciende del significado meramente sistemático, proyectándose como una manifestación juridica de la voluntad unitaria que subyace en el ordenamiento, y que se conecta con la legitimidad del mismo ${ }^{80}$. Se revela, así, como la base medular de la Constitución, de forma que: «Actuando la fórmula política, y los valores políticos contenidos en la Constitución", se verifica auténticamente la defensa de la misma en la dialéctica permanencia-cambio.

La transfiguración de la Constitución material en fórmula política no implica, en todo caso, la desaparición de aquélla, que subyace, permaneciendo siempre en un plano distinto a la Constitución formal.

La conexión entre ambas, podría reflejarse en base a relacionar la Constitución material con la que configuraría la fórmula política preconstitucional $^{81}$, que una vez reflejada en el plano jurídico, mediante la Constitución formal, se convierte en fórmula política propiamente dicha.

En esta opinión convergía MOSCA ${ }^{82}$ al referirse a que, cuando un determinado sistema de ideas políticas proyecta su influencia sobre el ordenamiento, imprime en éste su fórmula política específica, identificándolo.

Ahora bien, hay que señalar que el pensamiento de Mosca no llegaba al extremo de la incorporación propiamente jurídica de la fórmula política.

79 CROSA, E., «ll fattore político e le costituzione», en Scritti in onore di Oreste Ranelletti, Padua 1931, pág. 153

'so Lucas Verdú, P., «Problemática actual de la justicia Constitucional y del examen de la Constitucionalidad de las leyes", en Boletín informático del Seminario de Derecho Politico. Salamanca, mayo-octubre 1957, pág. 107.

B1 Canosa Usera, R., Identidad constitucional, interpretación y fórmula poIItica de la Constitución. Tesis Doctoral, Dirigida por el Profesor Lucas Verdú. Universidad Complutense, Madrid 1986, pág. 382. Publicada por el Centro de Estudios Constitucionales, Madrid 1989.

82. Mosca, C., Sulla teoria dei governi. Milán, Instituto editoriale scientifico, 1925. 
En otro caso, es perfectamente acoplable su pensamiento como precedente del significado jurídico con que posteriormente se reconoce a la fórmula política, al considerarla como el instrumento jurídico en que cristalizaría la Constitución material, de carácter extrajurídico.

Así, la decisión que adoptó la comunidad de convertirse en forma jurídico-política (Constitución), pasa, «De ser un proceso natural: el deseo sentido por la comunidad de ser y estar en Constitución, a su racionalización a través del derecho" ${ }^{83}$.

Esto conduce a que las modificaciones de prescripciones legalesconstitucionales que han asumido un valor emblemático - como consecuencia de servir de fundamento a la Constitución material- en la ingeniería constitucional ${ }^{84}$ del poder constituyente, integrando el elemento identificador específico de un determinado orden constitucional, cuya conculcación volvería a éste irreconocible, supongan, no una actividad simplemente revisora, y por ello atribuible al órgano constituido que opera la revisión, sino que transciende la actividad conferida a éste, para configurar función del poder constituyente como legítimo poder capacitado para pronunciarse al respecto. La variación del contenido de la Constitución material trasciende del órgano de revisión, ya que ésta está intimamente vinculada al acto de decisión de la voluntad política de una determinada comunidad ${ }^{85}$ : «Una facultad de reformar la Constitución, significa que una o varias prescripciones legal-constitucionales pueden ser sustituidas por otras, pero sólo bajo el supuesto de que queden garantizadas la identidad y continuidad de la Constitución como un todo".

Por consiguiente ${ }^{86}$ cuando se producen modificaciones que prescinden del respeto de las líneas esenciales del ordenamiento - o sea de la Constitución material-, se pierde la identificabilidad del Estado superior, subsistiendo, por el contrario, su identificabilidad, siempre que no se vulnere la Constitución material.

Pero el sentimiento que la norma suprema abriga no siempre es uniforme. Si la adhesión que suscita la norma ${ }^{87}$ no se refleja en la Co-

a3 Lucas Verdú, P., El sentimiento constitucional. Reus, S.A., Madrid 1985, pág. 68, op. cit.

34 RollA, G., Riforma delle istituzioni e Costituzione materiale. Giuffre, Milano 1980, pág. 135 y añade el autor, Rolla, pág. 105, que cualquier desviación del poder de revisión, que excediéndose de sus facultades, vulnerara la Constitución material se traduciría en una manipulación del sistema político que fue establecido por el poder constituyente originario. Por lo que se puede decir que la Constitución material actúa como elemento identificador, irreductible por vía de la revisión constitucional.

op. cit.

${ }_{85}$ Schmitt C., Teoría de la Constitución. Alianza Edit., Madrid 1982, pág. 119,

86 Bobio y Matteucci, N., Diccionario de política, op. cit., pág. 379.

${ }^{87}$ LuCAS Verdú, P., El sentimiento..., op. cit., pág. 68. 
munidad, las distintas fuerzas políticas que discrepen pretenderán, lógicamente, socavar los cimientos - la fórmula política- de la Constitución.

La fórmula política se revela, pues, siendo el elemento identificador de la Constitución formal, como el instrumento objetivo que define el sentir de la voluntad, mayoritaria asumida en el acto constituyente.

Las corrientes politicas, pues, seguirán operando y evolucionando, de forma más o menos afín a la Constitución formal, pero carecerán ya de la libertad absoluta que tuvieron en el momento de la decisión constituyente. De alguna manera configuran fuerzas constituidas ${ }^{88}$, al no gozar de la absoluta fuerza creadora constituyente.

\section{b) Elementos de la fórmula politica}

La fórmula política configura el elemento identificador de la norma fundamental del Estado ${ }^{89}$. A tal fin, nuestra Constitución ha reflejado este factor identificador en la fórmula política que se desprende del Preámbulo, Título Preliminar y algún artículo del Título $l^{90}$. Sin perjuicio de que la fórmula polftica se deduzca de los presupuesto señalados, el artículo 1.1. CE contiene los elementos más significativos de la fórmula de identidad del ordenamiento ${ }^{91}$ — perfilando sin duda la Constitución material ${ }^{92}$ - los cuales, aunque los tratemos a continuación de una manera diferenciada, guardan una estrecha coordinación: «Expresan la interconexión entre los tres elementos de la fórmula política" ${ }^{93}$, reflejando lo que configura la identidad específica, o la "Constitución de la Constitución, de nuestro ordenamiento, concretándose en ella la Constitución material ${ }^{94}$.

88 Canosa Usera, R., op. cit., pág. 383.

89 Crisafulli, V., I principi dell'interpretazione ed applicazione delle leggi. Padua, Cedam 1939, pág. 14.

so LUCAS Verdú, P., "Estado Social y democrático de derecho", en "Constitución Española de 1978. Comentario a las leyes políticas." Revista de Derecho Político. Dirigida por O. Alzaga Villaamil, tomo I, pág. 44. Edit. Derecho reunidas.

91 Alzaga Villaamil, O., La Constitución Española de 1978. Comentario sistemático. Ediciones del Foro, Madrid 1978, pág. 72; como señala con razón Alzaga: "Los diez preceptos configuradores del título preliminar, no tienen la misma naturaleza, ni pueden siempre considerarse como la médula de los tres elementos que integran la fórmula polítican. pág. 389.

92 LuCAs Verdu, P., Curso de Derecho Político. Vol. IV, Tecnos, Madrid 1984,

${ }^{93}$ Idem, «La fórmula política de la Constitución», en el Colectivo, Estudios sobre el proyecto de Constitución. Centro de Estudios Constitucionales, Madrid 1978, pág. 11, op. cit.

94 Rolla, G., Riforma delle istituzioni e Costituzione Materiale. Giuffré, Milano 1980, pág. 120, op. cit. 


\section{a) Techo ideológico}

Viene establecido por la enumeración de los principios fundamentales que conforman el sustrato en que descansa la específica caracterización jurídica, política, social y económica del régimen ${ }^{95}$, a las que VIRGA denomina declaraciones constitucionales.

Este elemento ideológico de la fórmula política que, a nuestro juicio, sirve de soporte a los restantes elementos de la misma, se deduce implicitamente del Estado social y democrático de derecho, quedando más claramente expresado en los valores superiores del artículo $1.1 \mathrm{CE}{ }^{96}$, que, como norma de apertura, anticipa los elementos de la fórmula política que luego van perfilándose en los siguientes artículos del Título Preliminar. Así, el Estado social y democrático de Derecho se especifica en el 9.2; el pluralismo en los artículos 2.3, 4.2, 6 y 7; la forma política del Estado, no en cuanto a Monarquia Parlamentaria, sino en cuanto a estructuración territorial del Estado, en el artículo $2 \mathrm{CE}$; mientras que la forma política como Monarquía Parlamentaria, además de venir establecida por el apartado 3 de la propia norma de apertura que diseña el artículo 1, viene especificada ya en el Título II.

Sin perjuició, pues, de que el elemento ideológico de la fórmula política impregne la totalidad de la fórmula identificadora de nuestro ordenamiento, nuestro documento constitucional contiene diversas referencias a factores ideológicos ${ }^{97}$, concretándose sobre todo en el artículo 1, como norma de apertura, así como en los artículos 6 y 7 y el Titulo I, definiendo una dimensión ideológica de marcada raigambre demoliberal socializada. Estos factores ideológicos se proyectan en todo el texto constitucional «influyéndolo», inspirando el telos constitucional de todo el ordenamiento.

Sin embargo, se comprueba que nuestro Estatuto fundamental viene configurado de antemano por la operatividad del consenso ${ }^{98}$ en que convergieron todas las fuerzas políticas, plasmándose tal manifestación tanto en la estrategia preconstituyente como en el propio texto en que cristalizó la obra constituyente, si bien, habría que señalar que dicho consenso no

95 VIRGA, P., Diritto Costituzionale. Giuffrè, ed. Milán 1979.

"Lucas Verdú, P., "Estado social y democrático de derecho", en La Constitución Española de 1978. Comentarios a la leyes políticas. Tomo I, dirigida por 0 . Alzaga Villaamil. Edersa, op. cit.

${ }^{97}$ Idem, Estimativa y Politica Constitucionales. Los valores y principios rectores del ordenamiento Constitucional español. Sección de Publicaciones de la Facultad de Derecho. Madrid 1984, pág. 61.

${ }_{96}$ Morodo, R., La transición Politica. Tecnos, Madrid 1984, pág. 129 y ss. 
configuró una realidad previa de afinidad ideológica ${ }^{99}$, sino un consenso de intereses de las fuerzas que estaban presentes en la etapa constituyente, y en virtud de su aceptación, se introducen en la norma fundamental las diversas opciones constitucionales surgidas de tales diferentes tendencias ideológicas.

La resultante, en todo caso, define el elemento ideológico al que se llegó en el consenso, y que se proyecta, como aduce el profesor LUCAS VERDU் ${ }^{100}$, en una dimensión demoliberal socializada, sin que ello suponga una adscripción ideológica previa del ordenamiento constitucional.

\section{b) Una estructura social determinada}

Este otro elemento configurador de la fórmula política se define en función de la concepción ideológica en que se materializó el consenso, de forma que su estructura socioeconómica está influida por el elemento ideológico ${ }^{101}$ que, como vimos líneas antes, constituye el soporte de la fórmula política. Cualquier adscripción ideológica lleva pareja una opción de organización económica, sin cuya puesta en práctica, dificilmente podrianse alcanzar los objetivos definidos en la fórmula política.

En este sentido, la estructura social que vislumbra nuestro texto fundamental, se deduce parcialmente de los valores superiores de libertad e igualdad ${ }^{102}$, y de la misma estructura social que condiciona el Estado de Derecho, y deriva, asimismo, de la conjunción ideológica de la tradición demoliberal y de ideales de origen socialista ${ }^{103}$. Con esta adjetivización del Estado de Derecho — como eje- de social y democrático, se posibilita la materialización efectiva de la estructura socio-económica a través del capítulo tercero ( $\mathrm{De}$ los principios rectores de la política social y económica") y del Título l, estableciéndose las bases para que el Estado cree unas condiciones de vida más justas.

Nuestra Norma Fundamental diseña un modelo, pues, socio-económico, de evidentes connotaciones neocapitalistas ${ }^{104}$, con tendencias so-

99 Gil Cremades, J. J., “Las ideologias en la Constitución Española de 1978", en el colectivo Estudios sobre la Constitución Española de 1978. Facultad de Derecho, Zaragoza. Pórtico, Zaragoza 1979, pág. 77.

100 Lucas Verdü, P., Estimativa y politica constitucionales, op. cit., pág. 63.

to1 Ibidem, pág. 65.

102 Lucas Verdú, P., Curso de Derecho Político. Vol. IV. Tecnos, Madrid 1984, pág. 353, op. cit.

103 Alzaga VillaamiL, O., La Constitución Española de 1978. Comentario Sistemático, op. cit., pág. 79.

104 LuCAS Verdú, P., Estimativa..., op. cit., pág. 62. 
cializadoras merced a la cláusula transformadora que deriva del artículo 9.2. En todo caso, dada la imposibilidad de que los derechos contemplados en este capítulo no configuran objeto de tutela jurisdiccional, el modelo diseñado por aquél puede, en alguna forma, distorsionarse si no se procede a una interpretación afín a la orientación inicialmente diseñada en la fórmula política.

\section{c) La organización politica}

Ésta viene definida en el artículo 1.3 configurando la Monarquía Parlamentaria, que configura la forma política del Estado -expresión poco feliz que ha suscitado la crítica en cierto sector doctrinal ${ }^{105}$ - como síntesis de la convergencia del Rey y del pluralismo político - fuerzas politicas-, de lo que puede deducirse, como señala el profesor LUCAS VERDU் ${ }^{106}$, que ambos, Monarca y fuerzas políticas, han coadyuvado a co-fundar el Estado, configurando aspectos capitales de la Constitución material.

\section{c) Subsistencia de la fórmula politica como elemento identiflcativo de la Constitución formal, en la dialéctica permanencia-cambio}

La Constitución se identifica, como vimos anteriormente, con la fórmula política en su estadio prejurídico [vide infra llla)], permaneciendo siempre, a pesar de su posterior transfiguración en un plano jurídico, al integrarse, bajo la forma de fórmula política, en la Constitución formal. Esta afirmación, en absoluto infundada, permite vislumbrar el especial relieve y significado que ésta asume, en orden a su reconocimiento como Instrumento que actúa de parámetro en la valoración de la Constitución formal. Su justificación derivaria, como vimos con anterioridad, por el hecho de que ésta realmente se presenta como fuente de validez del sistema ${ }^{107}$, ya que la Constitución material, al configurar el instrumento en el que conflu-

105 De Esteban, J., El régimen Constitucional Español. Vol. I, Labor, BarceIona 1980, pág. 56, quien afirma que «La monarquía en la actualidad es una forma de Gobierno y no de Estado".

106 LuCAS Verdú, P., "Estado social y democrático de derecho", en La Constitución Española de 1978. Tomo I. Comentarios a las leyes políticas, op. cit., página 86.

107 De Vergottini, G., Derecho Constitucional Comparado. Espasa-Calpe, Madrid 1983, pág. 143, op. cit. 
yen las diversas posiciones ideofógicas y tendencias políticas, determina, en el proceso preconstituyente, la decisión de la voluntad política ${ }^{108}$.

En este sentido, cabe aducir que la Constitución material capitaliza la legitimidad de la legalidad de la Constitución formal.

Estas dos afirmaciones sobre la Constitución material: su carácter de fuente de validez de la Constitución formal, de un lado, y por otra parte, el hecho por el cual la Constitución material configura el fundamento de la legitimidad de la legalidad formal, ya que se capitalizan en ella las fuerzas políticas existentes en el momento constituyente, conducen a la consideración de la Constitucion material, a través de su traducción jurídica, esto es: de la fórmula política, como elemento identificativo de la Constitución formal en la dlaléctlca permanencla-camblo.

Si en la Constitución formal se distingue una parte específica que concreta el fundamento sustancial del Estatuto constitucional anterior a la emanación de la Constitución formal, no puede por menos de reconocerse ${ }^{109}$ que los órganos constituidos no estarán capacitados para promover el cambio de la fórmula constitucional, al no disfrutar éstos el mismo poder que el que se reconoce y detenta el órgano constituyente del cual emanó el acto por el cual reciben su poder.

Por otra parte, al configurarse la Constitución material como el elemento identificador - a través de su manifestación juridica en la fórmula política- de la Constitución formal, toda vez que aquélla refleja la decisión constituyente ${ }^{110}$, no cabe predicarse de ella más que su subsistencia frente a la dialéctica permanencia-cambio, porque al configurar la fórmula política la voluntad decisionista en su manifestación previa y por lo tanto extrajurídica, no podría entenderse su cambio ${ }^{111}$ sino por cauces ajenos al derecho y fuera de todo vínculo juridico.

En otras palabras, la dialéctica permanencia-cambio en lo que afecta al contenido esencial o sustancial de la norma constitucional sólo cabe, a nuestro juicio, resolverse en base a la permanencia de la fórmula política frente al cambio, en consideración a los siguientes argumentos que, aten-

108 Kelsen, H., Teoría General del Derecho y del Estado. Universidad Autónoma de México, Textos Universitarios 1979, pág. 155. Afirma que «la noción de fuente del derecho sirve no sólo para designar los métodos de creación jurídica como la legislación y la costumbre, sino también para caracterizar procedimiento de elaboración y el contenido de la norma que ha de ser creada".

194.

109 Esposıto, C., La validitá delle leggi. Milano, Giuffré editore 1964, pág.

op. cit. ${ }^{111}$ Esposıto, C., La validita delle leggi, op. cit., pág. 197, cuando se refiere a la tesis mantenida por C. SCHMITT. 
diendo a un orden sistemático, podrían resumirse en los siguientes extremos:

a) Razones que explican la subsistencia de la fórmula política como elemento identificativo de la Constitución formal en la dialéctica permanencia-cambio en función a que ésta no es sino la manifestación jurídica en que se transfigura la Constitución material.

b) Razones que explican la subsistencia de la formula política como el elemento identificativo de la Constitución formal en la dialéctica permanencia-cambio, derivada de la configuración de la Constitución material como fuente de validez de la Constitución formal, ya que proyecta el conjunto de las posiciones ideológicas y políticas que determinan la decisión de la voluntad política.

c) Razones que justifican la subsistencia de los principios políticos en la dialéctica permanencia-cambio, derivados de la legitimidad que la Constitución material confiere a la legalidad de la Constitución formal, al capitalizarse en la Constitución material los factores determinantes de la decisión constituyente.

d) Razones que justifican la permanencia de la fórmula política dimanantes de la condición extrajurídica que asume el acto constituyente decisionista que cristaliza en la fórmula política, no pudiendo, en consecuencia, predicarse su cambio por cauces jurídicos constituidos.

La especial proyección que la fórmula política determina en la Norma Fundamental es decisivo, por cumplir cuatro funciones de capital importancia, que siguiendo a MARTÍNEZ SOSPEDRA ${ }^{112}$, podemos enunciar del modo que sigue:

1) Determina la identidad de la Constitución, al concretar su diferencia específica.

2) Fija y define las opciones Constitucionales y al hacerlo proyecta con claridad tanto la arquitectura y principios Constitucionales, como el régimen vigente.

112 Martínez Sospedra, M., Aproximación al Derecho Constitucional Español. La Constitución de 1978. Ed. Fernando Torres, Valencia 1980, pág. 20. 
3) Determina el límite de la reforma Constitucional, delimitando, en consecuencia, cuáles serian los preceptos modificables sin alteración de la identidad de la propia Constitución.

4) Fija unos criterios orientadores básicos para la interpretación de los preceptos de la propia Constitución.

De las consideraciones precedentes, cabe deducirse, a nuestro juicio, una consecuencia de especial significado en orden al tratamiento de límites al poder de reforma: la afirmación de la fórmula polítlca como límite objetivo absoluto a la función de revisión constitucional.

En este sentido, el dispositivo de reforma se revela como instrumento idóneo para acometer los cambios que precisan los ordenamientos constitucionales, pero, de otra parte, al activar una competencia ${ }^{113}$ que como facultad legal-constitucional, asume carácter limitado, no podrá excederse de su específica función revisora, revelándose, por su propia naturaleza limitada, como el instrumento de referencia, al objeto de delimitar el ámbito en que cabe producirse la modificación ${ }^{114}$, así como, por el contrario, proyectar el ámbito a partir del cual, habrá de definirse la permanencia de determinados postulados constitucionales. En otros términos, la consecuencia del diálogo permanencia-cambio, encuentra su mejor manifestación en la actividad revisora, la cual puede -en determinadas materias- proceder al cambio, pero deberá observar la permanencia frente a aspiraciones de modificación de aspectos concernientes a la fórmula política ${ }^{115}$ ya que excede tal actividad de su función limitada de revisión ${ }^{116}$, so pena de que se produzca el poco recomendable resultado de incurrir en una auténtica «desconstitucionalización del ordenamiento" ${ }^{117}$.

${ }_{113}$ Schmitt, C., Teoría de la Constitución, op. cit., pág. 118.

114 De Vergottini, G., Derecho Constitucional Comparado, op. cit., pág. 143.

115 Schmitr, C., Teoría de la Constitución, op. cit., pág. 94. En cuanto a concreción fundamental de la voluntad constituyente: «La decisión política implicada en la Constitución, no puede reobrar contra su sujeto ni destruir su existencia política».

116 Burdeau, G., Traite de Science Politique. Tome IV, Librairie Générale de Droit et Jurisprudence, Paris 1969, pág. 250.

${ }^{117}$ Spagna Musso, E., Diritto Costituzionale. Vol. primo, Padova-Cedam 1979, pág. 144, op. cit. 


\section{d) Consecuencias del reconocimiento de la fórmula política como el elemento identificador de la Constitución formal, en la dialéctica permanencia-camblo}

Al configurarse la Constitución material como presupuesto de validez de la Constitución formal ${ }^{118}$ habida cuenta que en aquélla los ordenamientos encuentran la legitimidad de su juridicidad o legalidad ${ }^{119}$, la fórmula política asume un doble significado en el ámbito de la reforma del Ordenamiento Constitucional:

- De una parte, determina la plasmación del acto constituyente de los factores reales de poder, asi como sociológicos e ideológicos, traduciéndolos en la Constitución formal. Esto supone proyectar jurídicamente lo que ya existía como realidad material.

- En segundo lugar, se perfila como parámetro básico e indispensable para detectar las posibles desconexiones entre la Constitución formal y la propia Constitución material, debido al carácter dinamizador de ésta ${ }^{120}$, frente a la estaticidad del Instrumento formal, al fin de evitar que la desarmonia entre Constitución formal y material, proyecte un resultado puramente nominal ${ }^{121}$.

La consecuencia del desequilibrio conduciría al resultado de privar a la Constitución formal de la legitimidad que aquella Constitución material le confirio ${ }^{122}$-al revelarse, como hemos señalado anteriormente, como fuente primígena de validez del Instrumento formal- ya que, como la fórmula política es coincidente con la Constitución material en su fase juridificada, ésta expresará los presupuestos esenciales de la legitimación democrática del régimen.

118 Mortatı, C., La Costituzione in senso materiale, op. cit., Giuffrè edit. 1940, págs. 87-89, y en el mismo sentido, MARTINES, T., Diritto Costituzionale. 3. ${ }^{a}$ ed., Giuffrè ed., Milano 1984, pág. 29. DE Vergotrini, G., Derecho Constitucional Comparado. Espasa-Calpe, Madrid 1983, pág. 143, op. cit.

119 Mortatı, C., La Costituzione in senso materiale, op. cit., pág. 88.

120 Heller, H., Teoría del Estado. México, Fondo de Cultura Económica, 1983, pág. 195, op. cit. 218.

${ }^{127}$ Loewenstein, K., Teoría de la Constitución. Ariel, Barcelona 1976, pág.

122 Lucas Verdú, P., Estimativa y política constitucionales. Universidad Complutense, Facultad de Derecho, 1984, pág. 188, op. cit. 
La fórmula política se configura, así, como el instrumento imprescindible en la dialéctica permanencla-cambio, para armonizar los desequilibrios entre la Constitución material y la Constitución formal, toda vez que Integra en sí misma la síntesis y confluencia de la Constitución en los dos sentldos referidos.

En esta línea, la fórmula política se proyecta, pues, como límite absoluto de revisión constitucional al margen de su carácter explícito o implícito, toda vez que «Su modificación sustancial rebasaría los límites del poder de revisión competiendo en consecuencia al poder constituyente" ${ }^{123}$.

Lo que nos conduce a sostener que la modificación de todo ordenamiento constitucional es perfectamente predicable, como no podría ser menos, incluso en sus presupuestos materiales configuradores del núcleo esencial del Instrumento fundamental, manifestado en la fórmula política, ahora bien, hay que destacar $-y$ esto es lo que determina la diferencia esencial entre una y otras posiciones doctrinales al respecto- que cuando la modificación afecta cualquiera de los elementos identificadores del texto constitucional, no cabe hablar ya de reforma constitucional, strictu sensu, a través de la cual se enervaría el poder constituido, y por lo tanto, limitado jurídicamente, sino que lo que se produce es una supresión ${ }^{124}$ del orden existente, porque el cambio se refiere "A las decisiones politicas fundamentales de la Constitución, lo que es asunto propio del poder constituyente». En definitiva, la revisión de la Constitución en cualquier aspecto concerniente a la fórmula política, habrá de producir un cambio «de» Constitución, y no una revisión Constitucional.

e) La fórmula política como elemento configurador de límite absoluto al poder de revisión

Siendo la fórmula política el núcleo identificador de toda Constitución y configurador de la Constitución material, no puede por menos de considerarse como límite absoluto de toda Norma fundamental ${ }^{125}$, frente a cualquier pretensión revisora que tuviera como finalidad la remoción del elemento identificador que la define, so pena, en caso contrario - como quedó demostrado con anterioridad-de que ese poder constituido y limitado, que

123 Lucas Verdú, P., Curso de Derecho Político. Vol. II, 2." ed., Tecnos, Madrid 1977, pág. 432, op. cit. 120, op. cit.

124 Schmitт, C., Teoría de la Constitución. Alianza Edit., Madrid 1982, pág.

125 Lucas Verdú, P., Curso de Derecho Politico. Vol. II, Tecnos, Madrid, 2." ed. revisada, 1977, pág. 533, op. cit. 
se activa en la función revisora, se equipare al poder constituyente, lo que hemos refutado con anterioridad.

Sin embargo, a pesar de la consideración del elemento identificador de la Constitución, o fórmula política, como un límite absoluto frente a cualquier pretensión revisora, no por ello hay que descartar la dinamicidad que conllevan, fundamentalmente dos, de los tres elementos integradores de la fórmula política, esto es, el techo ideológico y estructura social ${ }^{126}$, al intentar realizarse a través de su implantación e inserción en la realidad social, frente a la estaticidad del tercer elemento que se refiere a la organización del régimen político. En este sentido -y sólo en éste- son compatibles, en nuestra opinión, la idea de dinamicidad y permanencia.

En todo caso, la dinamicidad de aquéllos - a nuestro modo de verdebe ser entendida en el sentido de adaptabilidad o movilidad de toda ideología para asentarse en una determinada estructura social, alentando un específico orden político estable. El carácter dinámico de aquéllos, por lo tanto, no implica la posibilidad de ser reformados, ya que configuran parte esencial del elemento identificador, sino la simple cualidad de indirizzo, para lograr la institucionalización e implantación del elemento politico de la fórmula. Por otra parte, del análisis comparado de la Norma fundamental de Bonn y de la Constitución italiana, se desprende, asimismo, el reconocimiento de los elementos de la fórmula de identidad, configuradora del límite absoluto frente a cualquier actividad revisora que se active a través del poder constituido. En este sentido hay que mencionar el artículo 139 de la Constitución italina que aplica una cláusula igual a la de las Constituciones francesas de 1946 (IV República) y 1958 (V República), artículo 95 y 89 respectivamente, que excluyen del poder de revisión la fórmula política republicana, confiriendo así al elemento politico, de los tres integrantes de la fórmula política, un valor de límite insuperable por la actividad de reforma constitucional.

En el mismo sentido se pronuncia el artículo 112.2 de la Constitución Noruega de 1814, al atribuir al Parlamento la decisión de adoptar la enmienda propuesta... «Que no podrá contravenir los principios de la presente Constitución, sino referirse únicamente a modificaciones de preceptos singulares que no alteran el espíritu de la misma» ${ }^{127}$.

La contemplación de estos supuestos de Derecho comparado ratifican nuestra afirmación de reconocimiento de la fórmula política, que asume valor de límite absoluto, frente a la función revisora. Efectivamente, si nos atenemos al caso italiano, la fórmula política de la Constitución italiana

${ }^{128}$ Lucas Verdú, P., Curso de Derecho Político. Vol. II, Tecnos, Madrid, 2." ed. revisada, 1977, pág. 532, op. cit.

${ }^{127}$ Las Constituciones Europeas. Vol. II, Edición preparada por M. Daranas Peláez, Editora Nacional, Madrid 1979, pág. 1484. 
se manifiesta en los Principios Fundamentales de la Norma (arts. 1 a 12) y en los Derechos y Deberes de los ciudadanos (arts. 13-54); analizando el ejemplo alemán, habrá que atender a lo que HERRFAHRDT ${ }^{128}$ denomina "Unantastbares Verfasssungsminimum" o mínimum constitucional inquebrantable o inviolable, recogido en los artículos 1 y 20, referidos respectivamente a la inviolabilidad de la dignidad humana; reconocimiento de los derechos inviolables del hombre como fundamento - "Grundlage»- de toda comunidad, de la paz y la justicia, forma política y soberanía nacional.

Acordamos con el profesor LUCAS VERDÚ, que el constituyente italiano y el alemán adoptan el modelo de democracia liberal, asumiendo en él las modernas reivindicaciones sociales, en el que se plasman y conjugan los tres elementos de la fórmula política Imbricados de tal forma que se hace imposible la alteración (revisión) de alguno de ellos sin que quede afectado cualquier otro elemento del principio de identidad configurador de la Constitución material. En este sentido, a nuestro juicio, podemos afirmar que cada uno de los elementos que integran la fórmula política, de igual modo que los tres conjuntamente, se proyectan frente a la actividad revisora como límite absoluto de la misma.

Para asumir la precedente postura doctrinal, es decisiva la consideración del profesor MORATI ${ }^{129}$, al afirmar que el constituyente define una solemne proclamación de pricipios que individualizan un determinado orden como totalidad, distinguiéndolo de cualquier otro y adquiriendo una fisonomia política propia.

En este orden de cosas, la proclamación del carácter absoluto de los principios anteriormente mencionados, en los supuestos de Derecho Comparado, justificaría la afirmación de que -impuestos por el constituyente- pueden ser sustraídos al poder de revisión, al objeto de garantizar la permanencia de la suprema manifestación de la voluntad del Estado.

\section{f) La permanencia del elemento político de la fórmula de identidad como Instrumento de subsistencia del orden constitucional}

En estrecha relación con el reconocimiento -como quedó explicado en otro lugar del presente capítulo- de la diferencia existente entre la actividad directa de la creación de una Constitución nueva y la actividad

128 Lucas Verdú, P., Curso de Derecho Político. Vol. II, Tecnos, Madrid, 2." ed. revisada, 1977, pág. 532, op. cit.

129 MORTATI, C., Raccolta de Scritti, Studi sul potere constituente e sulla riforma costituzionale dello stato. Vol. I Milano Giuffré, edit. 1972, pág. 319, op. cit., 
simplemente revisora, hay que situar las transformaciones constitucionales que, de producirse, suponen una afrenta o ataque al núcleo basilar ${ }^{130}$, de modo tal, que su anulación conllevaría la caída, asimismo, de todo el orden, al cual sustenta.

Por esta razón, nos parece suscribible la postura doctrinal ${ }^{131}$ que, al igual que un nutrido ejemplo de Derecho constitucional comparado ${ }^{132}$, justifica la permanencia del elemento Estado de la fórmula de identidad, frente a la pretensión reformadora, y esto no será por la razón de que cuando una Constitución prohiba la alteración del régimen político, se esté proclamando la inmuiabilidad absoluta de la instituciones, sino por que se prohiba al órgano de revisión la facultad de operar reiormas que, por su naturaleza e imporíancia — como sería el supuesto de una revisión del elemento político de la fórmula política: régimen político, superan la competencia de un poder insêtútuido.

La cláusula la intangibilidad del régimen político se justificaría en este sentido en base a las siguientes razones:

- Por la naturaleza del órgano de revisión, que siendo un poder instituido, queda afecto al régimen establecido en la Constitución.

130 Mortati, C., Appunti di corso di istituzioni di Diritto pubblico 1984-49. Tomo II, Padova-Cedam 1949, pág. 375, op. cit.

${ }_{131}$ La intangibilidad del régimen por la actividad revisora ha sido objeto de discusión entre quienes como G. BURDEAU, niegan tal competencia al poder de reforma, el sector de la doctrina niega, a las prohibiciones expresas de revisar el régimen politico recogidas incluso en los propios textos constitucionales, valor jurídico, sin fuerza vinculante alguna para las generaciones futuras.

Propugnan la 1. ${ }^{\mathrm{a}}$ postura: BuRdeAU, G., Traité de science politique. T. IV, Librairie Genérale de Droit et Jurisprudence, Paris 1969, pág. 256; VedEL, G., Manuel de Droit Constitutionel. 149, pág. 117.

Sustentan la 2." posición doctrinal: Duguit, L., Traité de Droti Constitutionel. 2. ${ }^{a}$ ed., Tomo IV, pág. 539; Barthelemy y P. Duez, Lafferriere, citados por Burdeau, G., op. cit., pág. 265.

${ }_{132}$ En el constitucionalismo francés: Ley Constitucional de 14 de agosto de 1884 por la que se añadiría el artículo 8 de la Ley de 25 de febrero de 1875: "La forma republicana de Gobierno no podrá ser objeto de propuesta de revisión". La misma fórmula sería tomada con posterioridad por el artículo 95 de la Constitución francesa de 27 de octubre de 1946, así como por el artículo 89 de la Constitución Gaullista.

En el caso alemán, la Ley Fundamental de Bonn establece en su artículo 79-3 un remisión al artículo 20 , que, en materia de revisión constitucional, prohibe la modificación del régimen politico.

En el supuesto italiano: el artículo 139 prohibe la revisión que tenga por objeto la forma republicana de Gobierno, incluyendo de esta forma la cláusula de intangibilidad del régimen. 
- En base a que la reforma que atañera al régimen supondría un cambio de poder tal que socavaria las bases fundamentales del sistema político, de forma que, de producirse, lo que se efectúa es una supresión de la Constitución.

Aunque esta tendencia se vislumbra, apenas, en el período de entreguerras, ocupa una criterio bastante extendido con posterioridad al mismo ${ }^{133}$, considerando que excede de la función revisora, cualquier modificación que afecte a determinadas disposiciones que forman el sustrato básico en el que la norma fundamental se asienta.

- En tercer lugar, porque el poder de reforma, por su propia condición de poder constituido, queda vinculado al poder constituyente que lo determino, no pudiendo ${ }^{134}$ estructurar el Estado como quiera, sino atendiendo a los parámetros básicos configurados por el poder constituyente que lo definió.

En base a los anteriores argumentos, cabe, a nuestro juicio, afirmar con MORTATI, que la función revisora deberá ceñirse a los postulados fundamentales que la obra del constituyente determinó, y en consecuencia, el elemento determinante del núcleo fundamental o sustancial de cada ordenamiento constitucional habrá de coincidir necesariamente con el límite que ha de establecerse con el poder de revisión; en otras palabras: los límites que se reconocen -ya sean implícitos o expresos- a la actividad revisora, se corresponden precisamente, con el elemento identificador de un orden fundamental.

Siguiendo, entonces una deducción lógica, la Constitución material - fórmula política o núcleo de identidad- individualiza la fundamentación política de una voluntad constituyente, erigiéndose de esta forma, como sostiene ROLLA ${ }^{135}$, como parámetro para evidenciar la discontinuidad de la Norma fundamental cuyo núcleo de identidad sea vulnerado mediante la función revisora. $\mathrm{O}$, si lo proyectamos desde la perspectiva que venimos tratando, la determinación del elemento político de identidad de la Constitución, habrá de asumirse como límite absoluto ante cualquier pretensión

33 Constitución del Estado Rheno Palatino de 13 de mayo de 1946, que prohibe cualquier modificación que afecte al preámbulo o a los principios del artículo $1^{\circ}$ y 74 , pues se refiere a las bases de la filosofía social del régimen (artículo 129). Constitución de Wutemberg-Baden, de 24 de octubre de 1946, cuyo artículo 85 no admite las proposiciones de modificaciones constitucionales contrarias al espíritu de la Constitución.

Asimismo el artículo 129 de la Constitución de Hesse-Nassau frente a la modificación del principio democrático.

${ }^{134}$ Recasen Siches, L., Tratado General de Filosofía del Derecho. 6." ed., Porrua, México 1978, pág. 306.

135 Rolla, G., op. cit., pág. 105. 
revisora, ya que, de no ser así, la intromisión del poder constituido de revisión en un ámbito que no le compete, se traduciría, como asimismo sostiene ROLLA, en una manipulación del sistema político que el poder constituyente configuró ${ }^{136}$.

\section{f.1) La continuidad del elemento político identificador de la Ley Fundamental a través de la permanencia del factor ideológico.}

La afirmación anterior ${ }^{137}$, en virtud de la cual, la fórmula política se compone de elementos estáticos y dinámicos precisamente porque la dinamicidad de estos últimos posibilita su realización y desarrollo, nos conduce necesariamente a considerar un punto de convergencia entre el elemento político e ideológico de la fórmula política, que es el que atiende a la permanencia de este último, al igual que acontecía respecto al factor político ante cualquier previsión reformista, porque el elemento político del principio de identidad se nutre de los principios ideológicos que, en una estructura social le alientan. Todo texto fundamental, en la medida que reconozca la existencia de una Constitución material, se halla vinculado, de un lado, por su carácter dinámico, y de otro, por una perspectiva de continuidad ${ }^{138}$ del núcleo identificativo de aquel Código que las fuerzas políticas constituyentes propulsaron, en el momento de organizar políticamente una sociedad dada.

En este sentido, convenimos con ROLLA al afirmar que esta sintesis de dinamicidad y continuidad, se proyecta en torno a una perspectiva de fines, espectativas y programas propuestos por las fuerzas políticas dominantes en el proceso Constituyente, para cuyo desarrollo son englobados los principios ideológicos respecto a los que se produce el punto de convergencia de la permanencia de ambos elementos: político e ideológico a través del cual, el primero se viabiliza.

Es, en nuestra opinión, especialmente clarificadora la aseveración de ROLLA ${ }^{139}$, en esta posición que propugnamos, cuando afirma que la Constitución sustancial -que es equivalente, como venimos sosteniendo, a la fórmula de identidad - no se agota en la simple estructura normativa,

136 Así, por ejemplo, la Constitución italiana, ha cristalizado en una serie de principios básicos nucleares nítidamente distintos a aquellos otros que sustanciaron el precedente orden constitucional.

${ }^{137}$ Vide cap. V.C.e.

138 Rolla, G., Riforma delle istituzione e Costituzione materiale. Giuffrè edit. 1980, pág. 96, op. cit. En el mismo sentido Modugno: // concetto de Costituzione. pág. 205, op. cit. por RoLLA.

${ }^{139}$ RollA, G., Riforma delle istituzione e Costituzione materiale. Giuffrè edit. 1980, pág. 101 y ss, op. cit. 
ni en sus elementos técnicos, sino que cumple paralelamente una función ideológica integradora e interpretativa. En tal sentido, cabe, a nuestro parecer, afirmar que el elemento de identidad, en su doble vertiente política e ideológica, asume en sí una función de permanencia que escapa a los linderos de la dogmática positivista, configurando, en consecuencia, una específica e individualizada realidad constitucional, evitándose así que la Norma fundamental se refleje con una simple adición de normas aisladas, o singulares, sino configurándose como un conjunto unitario, coherente e interrelacionado en todas sus partes, en definitiva, como sostiene ROLLA ${ }^{140}$ : «El conjunto de principios que expresan y dan cuerpo a la idea de fuerza unitaria que anima la entera Constitución».

De todo lo anteriormente afirmado, podemos, como conclusión, aducir que el elemento identificador, aquello que verdaderamente significa la esencia material de una Norma fundamental, tanto en su vertiente política como en la ídeológica, de la cual aquélla se nutre - como apuntábamos en líneas anteriores- se revela, pues, como límite material que condicionará, en consecuencia, toda revisión de la Constitución, evitando así que una modiflcación determinada pueda alterar la validez general operada por la actividad constituyente.

Esta conclusión tiene, asimismo, eco en la teoría vertida por PIERANDREI ${ }^{141}$ cuando afirma que la Constitución gira en torno a un conjunto de principios generales que manifiestan el núcleo central, ya que expresan directamente: "Quei valori politici in cui la Costituzione stessa trova il suo fondamento, e per cui lo stato si caratterizza in modo peculíaren». De forma que la interpretación exacta de la Constitución, habrá de enterderse -como señalábamos con anterioridad-como un conjunto global, no limitado a la simple estructura normativa de elementos técnico-constitucionales, de los motivos políticos: "Che stano alla base dei diversi principi intesi como quei postulati fondamentali che, avendo animato il potere costituente, si sono tradotti nell'ordinamento e continuano a sostenerlo attraverso l'esperienza dei tempos ${ }^{142}$.

Una vulneración de cualquiera de estos dos elementos que configuran el fundamento basilar de la identidad del texto constitucional, por via de la función revisora, no podrá, pues, a nuestro parecer, calificarse de reforma constitucional toda vez que conculcando los principios que atañen al elemento identificador, se traduce en una supresión de la misma y no

140 Rolla, G., op. cit., pág. 97.

141 PeirandreI, $F$., “Interpretazione delle norma costituzionali in Italia», en Scritti di Diritto Costituzionale. Vol. II, Torino 1965, pág. 654.

${ }_{142}$ Ibid̄em, pág. 655. 
en una mera reforma, con lo que esta última implica de susbsistencia a través de la adaptabilidad ${ }^{143}$.

\section{f.2) Alcance de la función interpretativa e integradora de la fórmula de identidad en la Constitución}

El valor material asumido por la fórmula material o identificadora de la Norma fundamental adquiere una dimensión interpretadora ${ }^{144}$-tanto en su alcance político como ideológico- que condiciona, de manera constante, todo el ordenamiento, manifestándose así la fórmula de identidad como un instrumento permanente y último de control de la constitucionalidad sustancial de las leyes, de forma que tendrá el efecto de invalidar aquellas que contrasten con los principios propugnados en la misma por el poder constituyente.

$Y$, es precisamente por esta razón -en nuestra opinión-, por lo que están inmersos en la fórmula política determinados elementos: con la expresa intención de evitar que, con el desarrollo de futuras corrientes interpretativas, se vulneren los principios propuestos en sede constituyente y que identifican ideológica y políticamente un determinado orden constitucional.

De poco habría servido, en otro orden de cosas, los buenos deseos, $e$, incluso, el reconocimiento desde distintos sectores, durante el proceso constituyente español, dirigidos a proteger determinados postulados a través de un consenso por parte de grupos parlamentarios ${ }^{145}$, si pueden ser conculcados posteriormente merced a la atribución a la función revisora, de una prerrogativa que la desborda.

La función hermenéutica que asume la fórmula de identidad en todo ordenamiento fundamental, se proyecta, como dijimos en líneas ante-

143 Un ejemplo de tal supuesto lo brinda la reforma de la Constitución de 1812 que a través de su reforma se convertiría en la de 1837. La Comisión reformadora, presidida por Argüelles, presentó unas bases que definian la fisonomía de la Nueva Constitución y que reflejaban una absoluta sustitución y no reforma de la doceañista. Esto provocaría la protesta minoritaria del sector integrista doceañista: El Diputado Tarin presentó una proposición orientada a que las Cortes se limitaran a reformar y no a sustituir el texto de Cádiz.

Vide, Tomas Villarroya, J., Breve historia del Constitucionalismo Español. Centro de Estudios Constitucionales, 2." edic., Madrid 1982, pág. 49.

144 MortatI, C., Scritti sulle fonti del Diritto sull interpretatione. Giuffrè editore, Milano 1972, pág. 682.

145 LUCAS VERDÜ, P., "Singularidad del proceso constituyente español», en Revista de Estudios Políticos (Nueva Época), n. ${ }^{\circ}$ 1, enero-febrero 1978. Centro de Estudios Constitucionales, pág. 26. 
riores ${ }^{148}$, como un elemento que se hace sentir de manera constante a lo largo de todo el texto constitucional, condicionándolo. Pues bien, es precisamente esta cualidad predicable de la fórmula de identidad, la que explica su función integradora de la Norma fundamental, «toda vez que preside de manera coherente ${ }^{147}$ todas y cada una de sus partes, al objeto de integrarlo".

Esta función de la fórmula de identidad se justificaría, siguiendo al Prof. LUCAS VERDÜ, en atención a los siguientes motivos:

1) Porque configura lo que puede denominarse una norma sintetizadora de la decisión asumida en sede constituyente: su ideología, su organización y su estructura social.

2) Porque orienta todo el resto del ordenamiento fundamental en que se concreta ésta, vertebrando todo el resto del ordenamiento fundamental, proyectando un telos coherente del mismo, sin perjuicio, naturalmente, de que, como señala el maestro, la fórmula pueda deducirse de varios preceptos, tal y como ocurre en el artículo $1 .^{\circ}$ de la Constitución Española de 1978, que, siendo la norma de apertura y reflejándose en él la fórmula política, cabe, de igual modo manifestarse ésta, asimismo, en el Preámbulo, en el Título Preliminar y en algún artículo del Título $\mid$ y artículo 10. Si bien hay que reconocer que es precisamente en el artículo $1 .^{\circ}$ donde aparecen de forma claramente significativa los distintos elementos que reflejan fielmente la fórmula de identidad. En este sentido, no falta algún sector ${ }^{148}$ de la doctrina española que confiere a la fórmula de identidad la denominación de «Constitución de la Constitución», resumiendo así y reconociendo en ella, tanto el fundamento basilar de la propia Constitución como el carácter integrador de la misma.

Ésta ha sido, asimismo, la opinión mantenida de igual modo por algún sector de la doctrina italiana ${ }^{149}$, que al defender el significado inte-

pag. 384. Garrorena Morales, M., El Estado Español como Estado Social y Democrático de Derecho. Publicaciones Universidad de Murcia 1979, cita de Lucas Verdú, P., en Curso de Derecho Político. Vol. IV, Tecnos, Madrid 1984, pág. 384, op. cit.

149 Rolla, G., Riforma delle istituzione e Costituzione materiale. Giuffre, Milano 1980, pág. 120 y ss., op. cit. 
grador de la Constitución material está indirectamente admitiendo la función integradora de la fórmula de identidad en que aquélla cristaliza, al albergar los significados de las diversas disposiciones constitucionales, proyectándose como un canon interpretativo ${ }^{150}$ del propio texto constitucional:

De todo lo cual se deduce, como certeramente sostiene LUCAS VERDÚ, que la fórmula política o identificadora de un determinado orden constitucional, en la que se sintetiza la Constitución material, se revela como un instrumento inmediato de interpretación e integración del texto fundamental, tanto explícita como implicitamente ${ }^{151}$.

Como ejemplo ilustrativo del significado interpretativo, integrador o ideológico de la fórmula de identidad, cabe referirnos al supuesto de la segunda República, en que aquélla venia determinada por un Estado republicano, laico e integral, que aseguraba los derechos y libertades fundamentales, régimen éste cuyas características de república y laicidad, diferían de la caracterización del régimen anterior, distinguiéndole y caracterizándole según un perfil invidualizador propio.

De igual modo que la concepción e interpretación ideológica que identifica la Constitución de 1978 se concreta en el artículo 1, reflejando una configuración de régimen claramente opuesta al ordenamiento constitucional anterior.

Del alcance interpretativo e integrador que asume, pues, la fórmula identificadora de todo orden fundamental, podemos - a nuestro modo versacar una conclusión inmediata que se traduce en la afirmación de que la enunciación de los fines esenciales de la Constitución produce un efecto vinculante en todo el resto de la Norma fundamental, formando toda una unidad sistemática ${ }^{152}$. $\mathrm{Y}$ en este sentido, convenimos con MARTíNEZ SOSPEDRA ${ }^{153}$, al afirmar que, cuando la Constitución no se adecua a la opción definida por el modelo político concreto elegido por el poder constituyente, no puede seguir hablándose de Constitución en sentido propio,

150 Lucas Verdú, P., Curso de Derecho Político. Vol. IV, Madrid 1984, pág. 389, op. cit.

${ }_{151}$ Ibidem, pág. 391, op. cit.

152 Mortati, C., Scritti sulle fonti del Diritto e sul interpretazione. Costituzione e revisione. Giuftrè editore, Milano 1972, pág. 683, op. cit.

153 Martínez Sospedra, M., Aproximación al Derecho Constitucional español. La Constitución de 1978. Caracteristicas generales y fórmula politica de la Constitución de 1978. Fernando Torres editor, Valencia 1980, pág. 19, op. cit. 
ya que a ésta se le reconoce tal condición en la medida en que sus preceptos recogen adecuadamente los principios, normas y decisiones que definen el modelo político concreto, elegido por el poder constituyente. Si la identificación de dicha opción varía, ya no puede seguir existiendo coincidencia de fondo; se ha conculcado el carácter integrador que asume la fórmula de identidad, y con tal vulneración, se habrá producido la quiebra del sentido unitario del Código Fundamental.

Otra conclusión englobadora y común que se desprende de toda la argumentación elaborada en el presente capítulo, es la que nos conduce a refutar cualquier pretensión revisora que de algún modo atente contra cualquiera de los elementos basilares, que fundamentan la identidad propia del Código Fundamental, pues su conculcación vulneraría las cuatro funciones fundamentales que asume la fórmula de identidad de todo ordenamiento constitucional y que son reconocidas por un sector de la doctrina española ${ }^{154}$, de manera que el texto Constitucional se vería afectado por las siguientes contingencias:

1. En primer lugar habria desaparecido la identidad especifica de dicha Norma Fundamental que la diferencia de cualquier otra, toda vez que la fórmula de identidad determina singularmente un Orden Constitucional.

2. Asimismo se reflejaría una confusión en la fijación de la opción constitucional concreta de la Norma superior, puesto que la fórmula de identidad define claramente los principios constitucionales y las líneas maestras del régimen vigente.

3. No quedaría delimitado el poder de revisión, ya que la fórmula de identidad proyecta el limite de la actividad de reforma, definiendo qué preceptos no pueden ser objeto de modificación, precisamente por configurar el núcleo fundamental del texto, de tal forma que la conculcación de la fórmula de identidad, a través del simple poder de revisión, llevaria a la consecuencia de ignorar la existencia de límites a la actividad revisora, lo que supondria - llevando el razonamiento jurídico a sus últimas consecuencias- dotar al poder de revisión, que es competente únicamente para efectuar la reforma, de las características propias del poder constituyente, que es el que puede realmente y "soberanamente» hacer la revolución ${ }^{155}$.

154 Martinez Sospedra, M., Aproximación al Derecho Constitucional español. La Constitución de 1978. Fernando Torres editor, Valencia 1980, pág. 20, op. cit.

155 De Vega, P., La Reforma Constitucional y la problemática del poder constituyente. Tecnos, Madrid 1985, pág. 68-69. op. cit., 
La reforma de la Constitución no significa atentar contra la estructura basilar que identifica y define un ordenamiento específico, sino, tan sólo, acoplar y acomodar aquél a las nuevas exigencias histórico-políticas.

Todo lo que exceda de dicha función sería equiparar dos poderes diversos: poder constituyente y poder constituido, en una misma categoria, lo que conduce al absurdo resultado de atribuir al poder de revisión - que es un poder constituido y que obtiene su legitimidad del propio ordenamiento, siendo así competente únicamente para verificar operaciones de reforma que son funciones fundamentalmente jurídicas - competencias revolucionarias, ya que la supresión de la Constitución no compete al poder constuido sino al poder constituyente ${ }^{156}$.

De todo lo cual se concluye que la fórmula de identidad debe quedar sustraída a toda actlvidad revisora ya que su vulneración es competencia exclusiva del poder constituyente y no del poder constituido, erigiéndose aquélla como límite de la reforma constitucional.

4. Pérdida, en último término, de los criterios orientadores básicos para la interpretación de los preceptos de la propia Constitución, debido al carácter integrador que efectúa la fórmula de identidad.

\section{f.3) Disyuntiva del control de constitucionalidad de la actividad de reforma constitucional}

En relación al control de la constitucionalidad de la actividad revisora conviene plantearnos si aquélla cabe producirse desde una doble perspectiva: formal y material.

Veamos a continuación cómo se proyectarian estas dos manifestaciones de la jurisdicción constitucional en lo referente al tema de la revisión constitucional y, concretamente, en orden a la inconstitucionalidad que afectara al núcleo identificador de un orden constitucional.

La declaración de inconstitucionalidad de una reforma constitucional está íntimamente ligada a la cuestión de reconocimiento de la existencia de límites - ya sean expresos y tácitos-a tal actividad revisora, pero esta

156 Vide infra, para su argumentación juridica: Capítulo III. c de la tesis, en que se razona la antinomia de los dos conceptos del poder constituyente y constituido. 
afirmación se evidencia más en el supuesto del control de la constitucionalidad material, como veremos posteriormente.

El control de la constitucionalidad de la revisión en su manifestación formal está orientada a la declaración, por el órgano competente ${ }^{157}$, de si la reforma constitucional se ha producido cumpliendo o no el procedimiento establecido para su aplicación.

La posible inconstitucionalidad de una ley de revisión no suscitaría, pues, mayor problema que la determinación por parte de la jurisdicción, de si aquella reforma ha respetado o vulnerado el procedimiento formal, jurídicamente establecido para ejercirtarla.

Sin embargo, en el tema concerniente al control de la Constitución material, no puede decirse que la doctrina se muestre igualmente pacifica, pues frente a sectores, como el representado por el argentino POVINA ${ }^{158}$, que hace depender de la existencia de unos limites expresos la posible inconstitucionalidad material de la reforma constitucional que atentará contra aquéllos, otros sectores, como el representado por el profesor DE VEGA ${ }^{159}$, niega de raíz la hipotética inconstitucionalidad material de la reforma constitucional material, siempre que el texto fundamental silencie cláusula alguna de intangibilidad, contra la que pudiera esgrimirse la posible inconstitucionalidad material de la reforma. Esta posición, trasladada a nuestra Norma Fundamental, la explica el profesor DE VEGA de manera sucinta y clara: si el artículo 161.1,a de la Constitución se refiere a las leyes y actos, con fuerza de ley, susceptibles de atentar contra lo dispuesto en la Constitución, la ausencia en la Constitución de cláusulas de intangibilidad concretas, contra las que pudiera chocar la reforma constitucional, impiden toda posibilidad de plantearse tal supuesto de inconstitucionalidad material, de forma que el mencionado autor limita, en último término, el control de inconstitucionalidad de la reforma únicamente a aspectos formales y no materiales, si bien deja abierta, en todo caso, la posibilidad de control de la constitucionalidad material de la reforma a una categoría que califica como «controles políticos» en oposición a aquellos controles juridicos.

157 Kelsen, H., Teoria General del Derecho y del Estado. Textos Universitarios. Universidad Autónoma de México, México 1979, pág. 186. Para el autor, corresponde a la jurisdicción constitucional, entender únicamente de la inconstitucionalidad formal, lo que se traduce en que en caso de declaración de inconstitucionalidad de una ley de revisión por la jurisdicción constitucional, dicha inconstitucionalidad obedecerá al hecho de no haber seguido el procedimiento formal establecido constitucionalmente a tal fin y no por cuestiones de fondo y materia de la ley declarada inconstitucional.

${ }_{150}$ Poviña, J. R., "El poder constituyente, los jueces y la Constitución", en Revista de la Facultad de Derecho, n. 13 , pág. 232 y ss. citado por P. Lucas Verdú, Curso de Derecho Político. Vol. II, 2." ed., Tecnos, Madrid 1977, pág. 699.

159 De Vega, P., La Reforma Constitucional..., op. cit., pág. 302. 
Por otra parte, nuestro maestro LUCAS VERDÚ ${ }^{160}$, asume una po-. sición determinante al respecto, como consecuencia del reconocimiento de la fórmula política como un límite material, ya sea tanto de índole implícita como explícita, afirmando así que "La violación de cualquiera de estas limitaciones ofrece a nuestro juicio base suficiente para fundamentar la declaración de insconstitucionalidad por el órgano competente» lo cual afectaría obviamente a la constitucionalidad, en el aspecto material propiamente de la reforma constitucional.

Por nuestra parte, y sin entrar en la polémica de cuál seria el órgano competente para controlar la constitucionalidad de la reforma material - toda vez que el control de la constitucionalidad formal o procedimental no suscita polémica, como vimos con anterioridad-, convenimos con el profesor LUCAS VERDÚ, en la imperiosa necesidad de reconocer la existencia de una control de la Constitucionalidad material —al menos no jurisdiccional- de la actividad revisora. Esta observación la fundamentamos en los postulados siguientes:

1. En primer lugar por el papel que asume la actividad de reforma de garantía y defensa no jurisdiccional de la Constitución ${ }^{161}$, de manera que la ausencia de control de la constitucionalidad sobre dicha función de revisión conduciría al poco recomendable resultado de quebrar la labor garantística y de defensa de la Norma Superior que aquélla asume, y, además, porque al tratarse de una labor de garantia y defensa no jurisdiccional de la supremacia de la Constitución, nada impediria, a nuestro modo de ver, el reconocimiento de un control de la constitucionalidad material y no jurisdiccional, que se acoplaría perfectamente al carácter de defensa no jurisdiccional que, en todo caso, la actividad de reforma asume, condición ésta a la que hemos aludido en otro lugar del presente trabajo (vide cap. I-a).

2. Porque de este modo quedaria salvada la distinción del control sobre la constitucionalidad de la activida de reforma en sus dos posibles manifestaciones: formal, que coincidiria con la jurisdiccional, y material, que sería no jurisdiccional ${ }^{162}$, sin tener que incluir en una de estas dos categorias - en la formal- un control de inconstitucionalidad material, que

160 Lucas Verdú, P., Curso de Derecho Político. Vol. II, 2." ed., Tecnos, Madrid 1977, pág. 700, op. cit.

${ }_{161}$ DE OtTo PARdo, I., Defensa de la Constitución y Partidos Políticos. Centro de Estudios Constitucionales, Madrid 1985, pág. 26, op.cit.

162 Torres del Moral, A., Principios de Derecho Constitucional español. Vol. II. Átomo Ediciones, Madrid 1986, pág. 431. El citado autor distingue entre la garantía normal de la Constitución encarnada por la jurisdicción constitucional, de aquella otra que deriva de la reforma, como una garantía excepcional. 
seria inaceptable jurídicamente, ya que como certeramente señala DE VEGA ${ }^{163}$, la ausencia de claúsulas de intangilidad ${ }^{164}$, imposibilita que pueda hablarse, en rigor, de una inconstitucionalidad material, ya que el control político se circunscribe a aspectos jurídico-formales.

3. Por el apoyo que nos aporta la vacilante doctrina norteamericana, que al respecto, no ha sostenido una tendencia uniforme ${ }^{165}$, habiéndose, por el contrario, manifestado diletante en la declaración de inconstitucionalidad en lo concerniente a aspectos formales procedimentales de la actividad de la reforma - matters of procedure - o al contenido material de la misma - matters of substance-, por lo que no cabe, a nuestro juicio, negar categóricamente el control de la constitucionalidad material de la reforma, al margen de la designación de cuál sería el órgano competente a tal fin.

4. $Y$, por último, circunscribiéndonos al supuesto de nuestra Constitución de 1978, se da la circunstancia desafortunada de que la Ley Orgánica del Tribunal Constitucional en su artículo 27 soslaya, como señala DE VEGA ${ }^{166}$, el control constitucional del procedimiento del artículo 167 de la Constitución Española. En tal caso bien podría suceder que se recurriera al mencionado artículo, para que, por la vía del 167, se lleve a cabo cualquier reforma de los süpuestos previstos en el $168 \mathrm{CE}$, lo que, constituyendo una operación claramente inconstitucional, sin embargo, desde una consideración estrictamente jurídica, no sería reprobable. Todo lo cual, se traduciría, en último término, en que la función de defensa extrajurisdiccional que asume la reforma se queda convertida en papel mojado y sin eficacia alguna. Función ésta que, como señala GARCİA PELAYO ${ }^{167}$, se justifica en sí misma, por su propia coherencia juridica: «...Por tanto, una Constitución es la garantía de etos principios $y$, por consiguiente, todo lo que tienda a estos principios es constitucional, mientras que lo no tienda a ello no lo es».

De todo lo anteriormente referido sacamos una conclusión, a nuestro juicio inesquivable, y es que para que la función de defensa que asume la reforma constitucional no quede vacía de contenido, es imprescindible un efectivo control de la constitucionalidad de tal actividad reformista, tanto en su vertlente formal como material, para evitar que exista resquicio al-

163 De Vega, P., La Reforma Constitucional y la problemática del poder constituyente, op. cit., pág. 302.

164 En los textos fundamentales en que no se contemplen, tal y como acontece en nuestra Norma Superior.

165,166 DE VEGA, P., Reforma Constitucional y la problemática del poder constituyente, pág. 300, op. cit.

${ }_{167}$ Garcla Pelayo, M., Derecho Constitucional Comparado. Alianza Universidad, Textos, 1984, pág. 39. 
guno por el que puedan desaparecer o escapar las garantías con las que, a través del dispositivo específico de reforma constitucional, se dotan a las Constituciones escritas, precisamente para protegerlas de intereses esporádicos y pasajeros. Este control de la actividad de reforma se revela insuficiente si se limita a un mero control sobre dicha constitucionalidad, de carácter estrictamente formal, debiéndose, en consecuencia, aceptar paralelamente un control de la constitucionalidad material, que se torna, a nuestro parecer, imprescindible para que aquella labor de defensa que asume la reforma constitucional, se proyecte de manera integral en la doble vertiente formal y material, que asume todo texto fundamental, haciéndose posible así, como aduce ROLLA ${ }^{168}$ la reconducción de las distintas partes del texto constitucional, a la unidad sustancial del ordenamiento, como resultado de un proyecto unitario de construcción política. En este sentido rechazamos las posturas de quienes como SPAGNA MUSSO ${ }^{169}$ atribuyen únicamente al procedimiento rígido para la reforma, el carácter de defensa y garantía del instituto de reforma, toda vez que, como hemos visto, es suficiente la ínconstitucionalidad formal derivada de no seguir el procedimiento normal de revisión, para que pueda predicarse con verdadero fundamento, el papel de defensa y garantía de la Constitución de indole extrajurisdiccional, que asume el instituto de reforma de la Constitución, entendida así en toda su magnitud, al configurar un todo unitario congruente ${ }^{170}$ y que responde a garantizar la admisibilidad de limites a cualquier acción que implique, como aduce ROLLA, desprotección de algún tipo de los objetivos establecidos en la Constitución.

\section{f.4) Fórmula de identidad como instrumento de control politico de la constitucionalidad extrajurisdiccional}

Tal y como ha sido afirmado con anterioridad, el control de la constitucionalidad material de la reforma de la Constitución, no puede ser efectuada más que por vía extrajurisdiccional, y tal aseveración lleva aparejada una consecuencia que, a nuestro modo de ver, se torna imprescindible para el logro de tal objetivo, esto es: reconocer en la cláusula de identidad constitucional un instrumento de control, de carácter extrajurisdiccional de la Constitucionalidad material de la reforma, para que el papel que juega el instituto de reforma, como medio de defensa extrajurisdiccional de la Constitución, - como afirma un sector de la doctrina, visto con anterioridad-

168 Rolla, G., Riforma delle istituzione e Costituzione materiale. Centro de Estudios Constitucionales, Madrid 1980, pág. 96, op. cit.

${ }^{169}$ Spagna Musso, E., Diritto Costituzionale. Principi generali. Padova-Cedam 1979. Vol. I, pág. 103, op. cit.

170 Rolla, G., Riforma delle istituzione e Costituzione materiale. Centro de Estudios Constitucionales, Madrid 1980, pág. 103, op. cit. 
sea real y efectivo en su totalidad, esto es: formal y material, ya que, como indica ROLLA ${ }^{171}$, «La trascendencia de tal concepción garantista ha de proyectarse como un entramado unitario que tipifica específicamente un orden constitucional determinado»... «Asi, esta tendencia garantista, se presenta como una predisposición a la permanencia, que se fundamenta en conferir validez general de continuidad a determinadas manifestaciones del poder constituyente».

De manera que con el control de constitucionalidad formal exclusivamente de la reforma, no se consigue el objetivo de defensa extrajurisdiccional de la Constitución que la reforma asume, revelándose claramente insuficlente, si no se reconoce paralelamente la existencia de un control de la constitucionalidad material, y para lo cual la fórmula de identidad se manifiesta - a nuestro parecer - como el instrumento idóneo -imprescindible-, y determinante, en suma, de los supuestos de inconstitucionalidad material de la reforma constitucional.

Y ello es explicable por cuanto, como señala LAVAGNA ${ }^{172}$ la función de garantía contitucional (que asume la reforma) puede desprenderse del propio sistema constitucional, considerado como un conjunto unitario, al estar dotado de un equilibrio que imposibilita la verificación de alguna disfunción o eventual cambio, que lleve parejo el peligro de perturbar gravemente la conservación de dicho ordenamiento.

\section{Necesidad y justificación de su reconocimiento}

La necesidad de atribuir a la fórmula de identidad esta cualidad de configurarse como un instrumento de control de constitucionalidad material de índole extrajurisdiccional, se justifica por la circunstancia de ser la Constitución el resultado de un compromiso de las distintas fuerzas políticamente operativas; lo que conduce inevitablemente - como aduce PÉREZ ROYO ${ }^{173}$ - a reconocer en el propio texto garantías de permanencia a través de los procedímientos de reforma.

Sin embargo, a nuestro parecer, la garantia de permanencia que ha de presidir todo texto constitucional, no queda suficientemente asegurada con la atribución constitucional de un procedimiento más o menos gravoso, para efectuar la reforma de la misma, puesto que, superado aquél, nada

171 Rolla, G., Riforma delle istituzione e Costituzione materiale. Centro de Estudios Constitucionales, Madrid 1980, pág. 96, op. cit.

172 Lavagna, G., Diritto Costituzionale. Vol. I., Doctrine generali. Milano, Giuffrè editore, 1957, pág. 329 y ss.

173 Pérez Royo, J., La Reforma de la Constitución. Publicación del Congreso de los Diputados, Madrid 1987, pág. 189. 
obstaculizaria el suprimir y no simplemente reformar, la Constitución material, en el supuesto de que no existan cláusulas de intangibilidad en el ordenamiento constitucional afectado.

De lo que infiere, a nuestro parecer, el doble papel que ha de asumir la actividad de reforma: de un lado posibilitar la evolución, y de otro garantizar la permanencia. Esta dualidad lejos de ser paradójica, es sin embargo, la que debe presidir todo ordenamiento para que éste no quiebre. Llegados a este punto es cuando cabe plantearse la cuestión acerca de si la función de garantía de permanencia, que asume la actividad revisora paralelamente a la de viabilizar la adaptación del texto fundamental a nuevas proyecciones no queda suficientemente afianzada por los simples procedimiento formales -toda vez que como señalábamos con anterioridad, una vez superados éstos ${ }^{174}$ nada obstaculizaria atentar contra el principio identificador que define un determinado orden constitucional, provocando la quiebra del mismo- nada se opondria a nuestro entender, a asignar a la formula de identidad, el papel de instrumento, a través del cual subsiste la defensa del orden constitucional por la vía extrajurisdiccional y en el orden material.

\section{Carácter subsidiario de la fórmula de identidad en el control de la constitucionalidad extrajurisdiccional}

Hemos visto en otro apartado del presente trabajo cómo el constituyente una vez cumplida su obra, confía a otros la custodia de la misma, para que se continúe en el tiempo la voluntad expresada por él, proveyendo, asimismo, los medios de revisión que contribuyen a conservar el núcleo fundamental que caracteriza la Constitución. Pues bien, además de la jurisdicción constitucional que, como vimos con anterioridad, entendería de la constitucionalidad formal de la leyes, el constituyente dota al texto fundamental del dispositivo de reforma constitucional, como medio extrajurisdiccional para proveer -mediante procedimientos específicos- a la defensa del orden constitucional.

Pero si, como afirmábamos líneas antes, estos procedimientos, aun los más gravosos, no llegan a garantizar la supervivencia del núcleo fundamental, se torna, en nuestra opinión, imprescindible, el recurso a un tope

174 De hecho, Burdeau afirma que no son las mayores o menores dificultades procedimentales las que aseguran a las leyes fundamentales su relativa permanencia: los complicados mecanismos imaginados por los Constituyentes de 1791 y 1793 no impedirían su modificación, y por el contrario las Leyes Constitucionales de 1875 , cuya revisión era muy flexible, han durado mucho más. BuRDEAU, G., Traité de Science politique. Labrairie Generale de Droit et de Jurisprudence, Paris 1969, págs. 200-201. 
- límite, que impida la desintegración de la Norma suprema a través de su desconstitucionalización.

En este orden de cosas, no parece predicable la postura de MORTATI ${ }^{175}$ quien relega la elección de una forma u otra de garantía y defensa, en función de las condiciones del ambiente, del cual depende su grado de operatividad.

Si conectamos esta afirmación con la teoria aportada por Ignacio DE OTTO ${ }^{176}$, al señalar que el orden constitucional se defiende con su propio funcionamiento correcto, sobre una base social, económica y política adecuada, con la primacia del derecho social y la creación de una conciencia constitucional, podemos concluir que lo que se está haciendo, no es sino reconocer el papel indirecto que juega la propia Constitución material resumida en la fórmula de identidad, en aquella función de defensa y garantía del orden constitucional que la actividad revisora comporta.

Así pues, la fórmula de identidad se revela, a nuestro modo de ver, como punto de referencla decisivo y verdadera piedra angular en relación al control de constitucionalidad material de orden extrajurisdiccional, y esta afirmación, cabe sostenerse en una doble perspectiva: por una parte, en relación al control que verificará tanto en el supuesto de que existan cláusulas de intangibilidad expresas como en el caso de que no existan. $Y$ en el último caso, es donde, precisamente, se aprecia con más nitidez el carácter de instrumento de control que asume la fórmula de identidad en la función de defensa extrajurisdiccional, toda vez que, aunque no exista disposición juridica alguna, en un ordenamiento constitucional que pudiera ser vulnerada por la función de reforma ${ }^{177}$, no obstante, la Constitución material determinada en la fórmula de identidad, subyace y se proyecta tácitamente en orden a delimitar el control de constitucionalidad material y defensa extrajurisdiccional de la actividad revisora.

En todo caso, hay que matizar la afirmación anterior en el sentido de que la fórmula de identidad proyectada hacia la defensa extrajurisdiccional del orden constitucional a través de la reforma asumiria, en nuestra opinión, una posición subsidiaria en los supuestos en que existieran límites - claúsulas de intangibilidad expresas - si bien serian coincidentes con la fórmula de identidad, ya que aquéllos, al estar expresamente reconocidos en el texto fundamental, efectúan una función directa de defensa extrajurisdiccional del orden constitucional en el ámbito material.

\footnotetext{
175 MortatI, C., Scritti sulle fonti del Diritto e sull interpretazione. Vol. II, Milano, Giuffré edit. 1972, pág. 17, op. cit.

${ }_{176}$ De Otto PaRdo, I., Defensa de la Constitución y Partidos Políticos. Centro de Estudios Constitucionales, Madrid 1985, pág. 34, op. cit.

177 De Vega P., La Reforma Constitucional y la problemática del poder constituyente. Tecnos, Madrid 1985, pág. 302, op. cit.
} 
Y en este sentido la fórmula de identidad habrá de entenderla, en nuestra opinión, como el nudo del orden constitucional, a través del cual, se posibilitan los mecanismos de defensa del carácter super-legal de la Constitución que el instituto de reforma asume, así como de defensa del contenido político de la ley fundamental, como afirma MARTINEZ SOSPEDRA $^{178}$. De hecho tal aseveración, no hace sino abundar en la preocupación que se detecta en el ámbito académico y cultural angloamericano por la defensa de un "constitucionalismo sustancial» ${ }^{179}$, como medio de freno del poder, sumisión al derecho y protección de las libertades de los ciudadanos.

En la misma proyección se manifiesta MORTATI ${ }^{180}$ cuando confiere al instituto de revisión, la cualidad de instrumento de garantia no jurisdiccional, puesto que tiende a preservar la integridad del documento en que se consagra la voluntad suprema. De esa forma, justifica la ubicación del poder de revisión en el ordenamiento italiano, en el Título VI, dedicado a las garantias Constitucionales, asumiendo asi el poder de revisión una naturaleza de co-participación en la actividad jurisdiccional del juez constitucional «para la defensa de la integridad del núcleo fundamental que caracteriza la Constituciónn.

Asimismo, reconoce el mencionado autor que el simple hecho de confiar a un procedimiento especial la revisión de un texto fundamental -en el supuesto de las Constituciones rígidas - se traduce en atribuir a la actividad revisora la función de preservar y defender la Norma fundamental, inluso más aún —señala MORTATI_ que la de prever su reforma, como medio de maniener firme el núcleo de principios que la individualizan ${ }^{181}$.

De todo lo anteriormente expuesto podemos sacar una conclusión insoslayable, en el sentido de que al presentarse la Constitución material - que se concreta en la fórmula de identidad que individualiza un orden constitucional determinado- como fuente de validez del sistema, tal y como señalábamos en otro apartado del presente trabajo, aquélla se erige como instrumento que garantiza la unidad interpretativa e integradora del ordenamiento, act̂uando como parámentro delimitador de los topes de con-

178 Martínez Sospedra, M., Aproximación al Derecho Constitucional español. Colección Ciencias Sociales. Editor Fernando Torres, Valencia 1980, pág. 261. 261, op. cit.

179 Pereira Menaut, A. Carlos, En defensa de la Constitución. Edc. Universidad de Navarra S.A., Pamplona 1986, pág. 463-464.

180 Mortati, C., Istituzione di Diritto Pubblico. Tomo II, Nona edizione, Padova-Cedam 1976, pág. 1223-1225, op. cit.

${ }_{181}$ Tal ha sido sin duda la tendencia del constituyente italiano que ha puesto el acento en la función de conservación, más que en la de cambio a través de la fórmula revisionista. 
tinuidad e identidad de todo ordenamiento, subrayando los principios constitucionales sustanciales que configuran una Constitución de forma unitaria y permanente.

$Y$ puesto que la actividad revisora, como hemos expuesto anteriormente, asume una función de defensa de la Constituión, se llega al resultado de que la fórmula de identidad -en que queda plasmada la Constitución material y, por tanto, no objeto de revisión por el poder constituido de reforma- al configurarse como límite absoluto al poder constituido de revisión, adquiere un especial relieve, al configurarse como verdadera piedra angular en la delimitación de los preceptos reformables y no reformables, so pena de que el instituto de revisión pierda su función de defensa de la Constitución, que como vimos anteriormente con MORTATI, DE OTTO PARDO, MARTÍNEZ SOSPEDRA, entre otros, comporta tal actividad revisora,

Y no podría ser de otra manera, pues, a nuestro parecer, la recopilación en un texto escrito de la selección de unos principios fundamentales atendiendo a criterios racional-normativos, propia de la ideología liberal, conlleva ${ }^{182}$ un carácter de garantía de la racionalidad y certeza, que no abrigan, sin embargo, las Constituciones consuetudinarias; y de otra parte, la tendencia contemporánea hacia la rigidez de los ordenamientos constitucionales, no hace - en nuestra opinión - sino abundar en la postura de quienes reconocemos en el instituto de reforma uno de los instrumentos más idóneos para garantizar el respeto y la permanencia del texto constitucional, a través del cual las modificaciones y adaptaciones de la norma suprema no se imposibilitan ${ }^{183}$, pero la garantizan sin embargo la subsistencia de aquélla, al actuar la fórmula de identidad como parámetro determinante de hasta dónde puede llegar la reforma sin que la revisión Implique supresión.

182 De VergottinI, G., Derecho Constitucional Comparado. Espasa-Calpe, Madrid 1983, pág. 136.

183 Enciclopedia del Diritto, IX, Voz: Costituzione, Giuffrè editore 1982. 